\title{
Evolution of Atomic-Level Structure in Sub-10 Nanometer Iron Oxide Nanocrystals: Influence on Cation Occupancy and Growth Rates
}

Susan R. Cooper ${ }^{\dagger}$, Randall O. Candler ${ }^{\dagger}$, Alexia G. Cosby ${ }^{\dagger}$, Darren W. Johnson ${ }^{\dagger}$, Kirsten M. Ø. Jensen ${ }^{*^{*}}$ and James E. Hutchison ${ }^{\dagger *}$

†Department of Chemistry and Biochemistry and Materials Science Institute, 1252 University of Oregon, Eugene, Oregon 97403-1253, United States

Department of Chemistry, University of Copenhagen, Universitetsparken 5, DK 2100

Copenhagen, Denmark

*Corresponding author: hutch@uoregon.edu (Hutchison, J. E.) and kirsten@chem.ku.dk

(Jensen, K. M. Ø.)

A
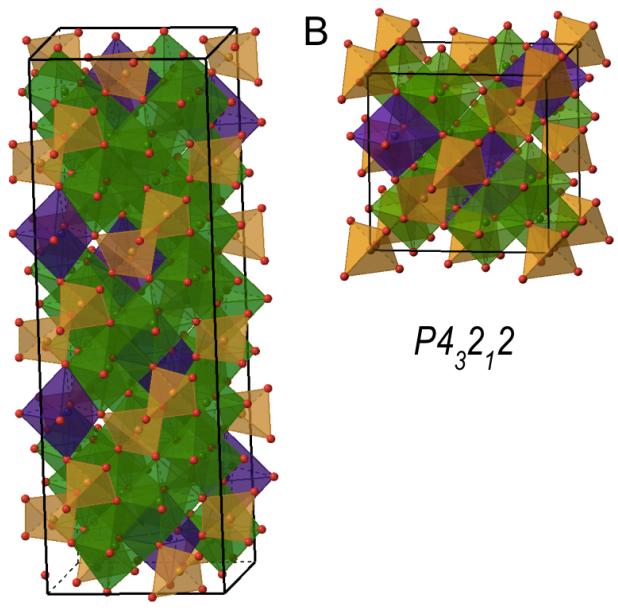

$P 4_{3} 2{ }_{1} 2$
C

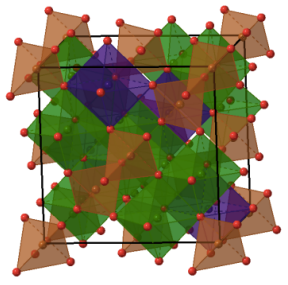

$\mathrm{P}_{3} 3_{2}$

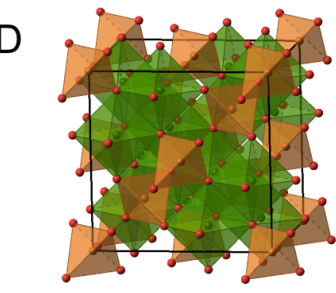

$F d-3 m$

$P 4,2,2$

Figure S1. Polyhedral figures of four structural models compared in this work that take four different space groups. The red spheres are oxygen, yellow cations are tetrahedrally coordinated cations, green octahedra are octahedrally coordinated cations and purple octahedra are octahedrally coordinated cations that are vacant in the maghemite phase of spinel iron oxide. A) Structural model taking the space group $P 4_{1} 2_{1} 2$, B) Structural model taking the space group $P 4_{3} 2_{12}$, C) Structural model taking the space group $P_{4} 3_{2}$, and D) Structural model taking the space group $F d-3 m$. Structures were generated using published cif files with Crystal Maker version 10.0.7. 
Table S1: The nanocrystal (NC) size determined by three different methods: PDF, SAXS and TEM. The diameter was determined by PDF refinement using a structural model taking the space group $P 4_{3} 2_{1} 2$. The sizes were determined by SAXS for eight samples assuming a spherical form factor, a dilute structure function and a Gaussian distribution. Core diameters were also determined from TEM images. Size analysis using FIJI software ${ }^{1}$ yielded the size and dispersity of four samples across the size series that corroborated the diameters determined by PDF.

\begin{tabular}{ccc} 
PDF Crystallite Diameter (nm) & SAXS Diameter (nm) & TEM Diameter (nm) \\
\hline 3.0 & -- & -- \\
3.6 & -- & -- \\
3.8 & $4.4 \pm 0.4$ & $3.5 \pm 0.9(189 \mathrm{NCs})$ \\
3.8 & -- & -- \\
3.6 & $5.0 \pm 0.2$ & -- \\
4.8 & $5.3 \pm 0.3$ & -- \\
4.5 & -- & -- \\
4.5 & -- & -- \\
4.5 & -- & - \\
5.4 & $5.9 \pm 0.6$ & - \\
6.1 & $6.6 \pm 0.6$ & $7.3 \pm 1.2(180 \mathrm{NCs})$ \\
7.4 & $7.9 \pm 0.9$ & -- \\
6.2 & -- & -- \\
6.9 & $8.0 \pm 1.1$ & - \\
7.4 & $9.2 \pm 0.9$ & $9.2 \pm 2.5(125 \mathrm{NCs})$ \\
7.6 & $8.8 \pm 1.1$ & -
\end{tabular}
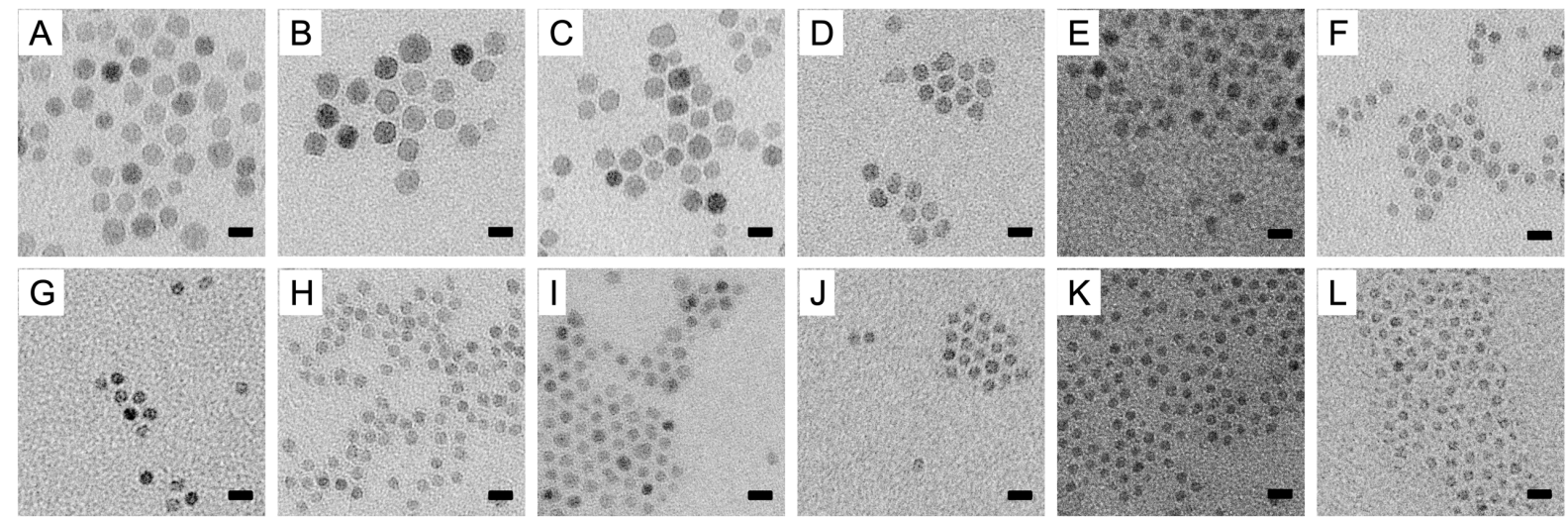

Figure S2. TEM images for 12 samples with core diameters from 7.6-3.6 nm determined by PDF. A) $7.6 \mathrm{~nm}$, B) $7.4 \mathrm{~nm}$, C) $7.4 \mathrm{~nm}$, D) $6.1 \mathrm{~nm}$, E) $5.4 \mathrm{~nm}$, F) $4.5 \mathrm{~nm}$, G) $4.5 \mathrm{~nm}, \mathrm{H}) 4.5 \mathrm{~nm}$, I) $4.8 \mathrm{~nm}$, J) $3.6 \mathrm{~nm}, \mathrm{~K}) 3.8 \mathrm{~nm}$ and L) $3.6 \mathrm{~nm}$. The scale bar in each image is $10 \mathrm{~nm}$. 

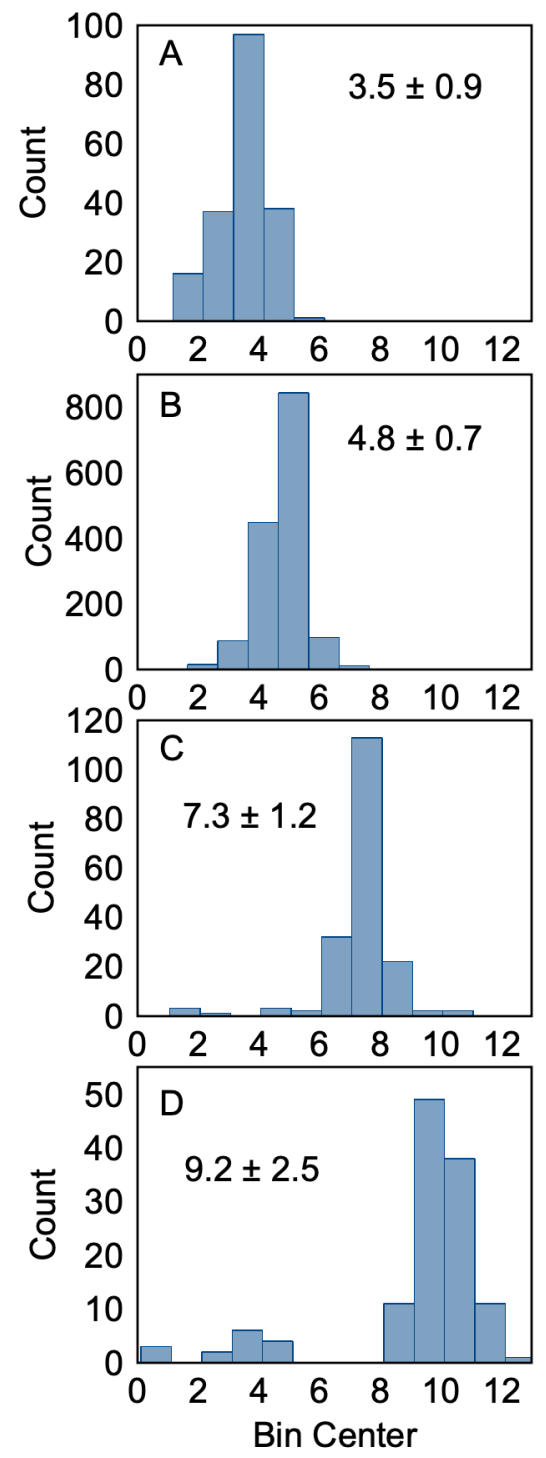

Figure S3. Histograms of the core diameter of NCs of four samples across the size series. In A-D the size determined by TEM size analysis using FIJI software is included. 

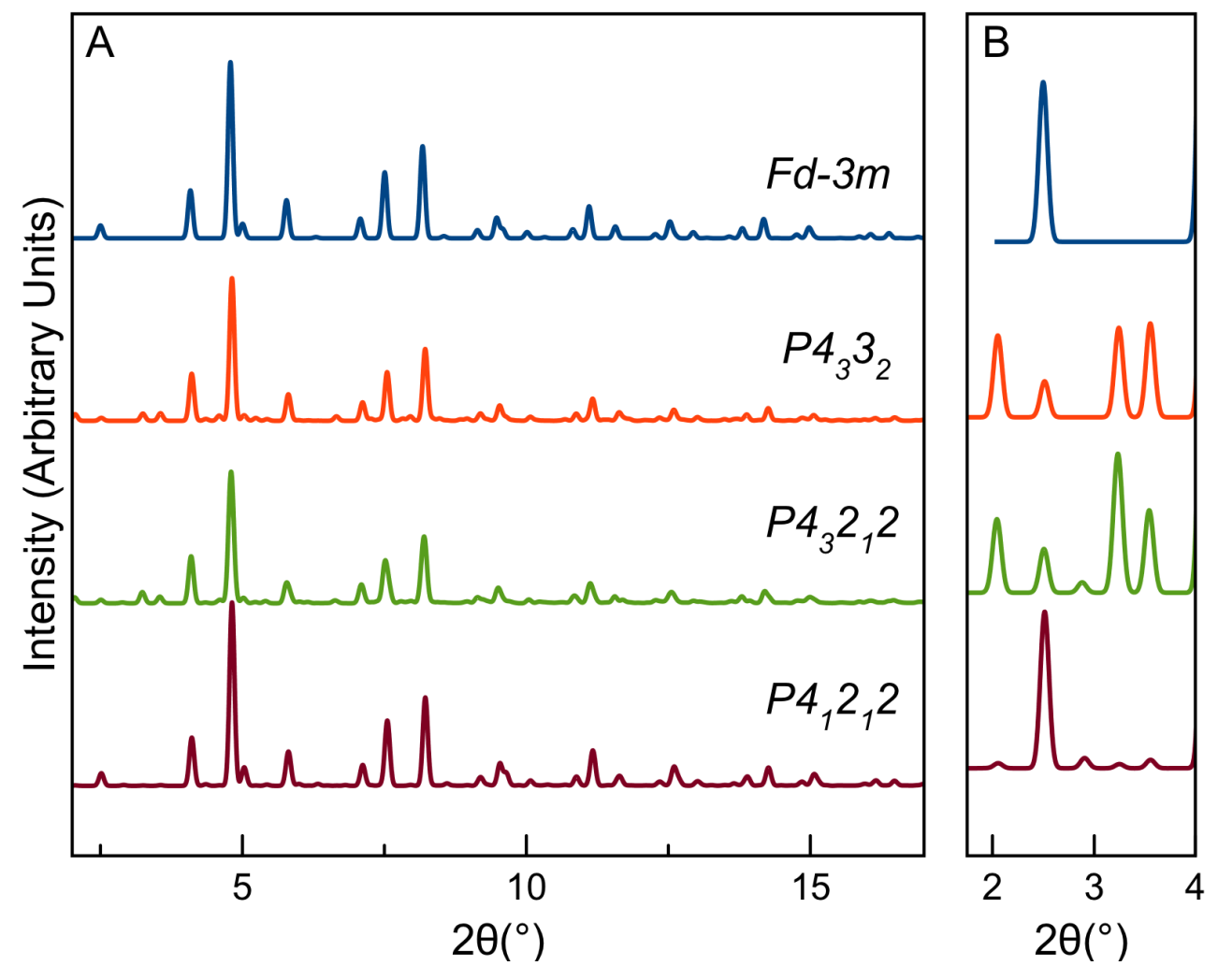

Figure S4. Calculated XRD patterns of four crystallographic models reported in the literature displayed using CrystalDiffract software 6.7.2. Calculated XRD patterns are displayed (A) from $2^{\circ}-17^{\circ}$ and (B) from $1.7^{\circ}-4^{\circ}$. Figure B displays the superstructure at low angles. From top to bottom crystallographic models are $\mathrm{Fd}-3 \mathrm{~m},{ }^{2} \mathrm{P} 4_{3} 3_{2},{ }^{3} \mathrm{P}_{3} 2_{1} 2^{4}$ and $\mathrm{P}_{1}{ }_{1}{ }_{1}{ }_{2}{ }^{5}$ 


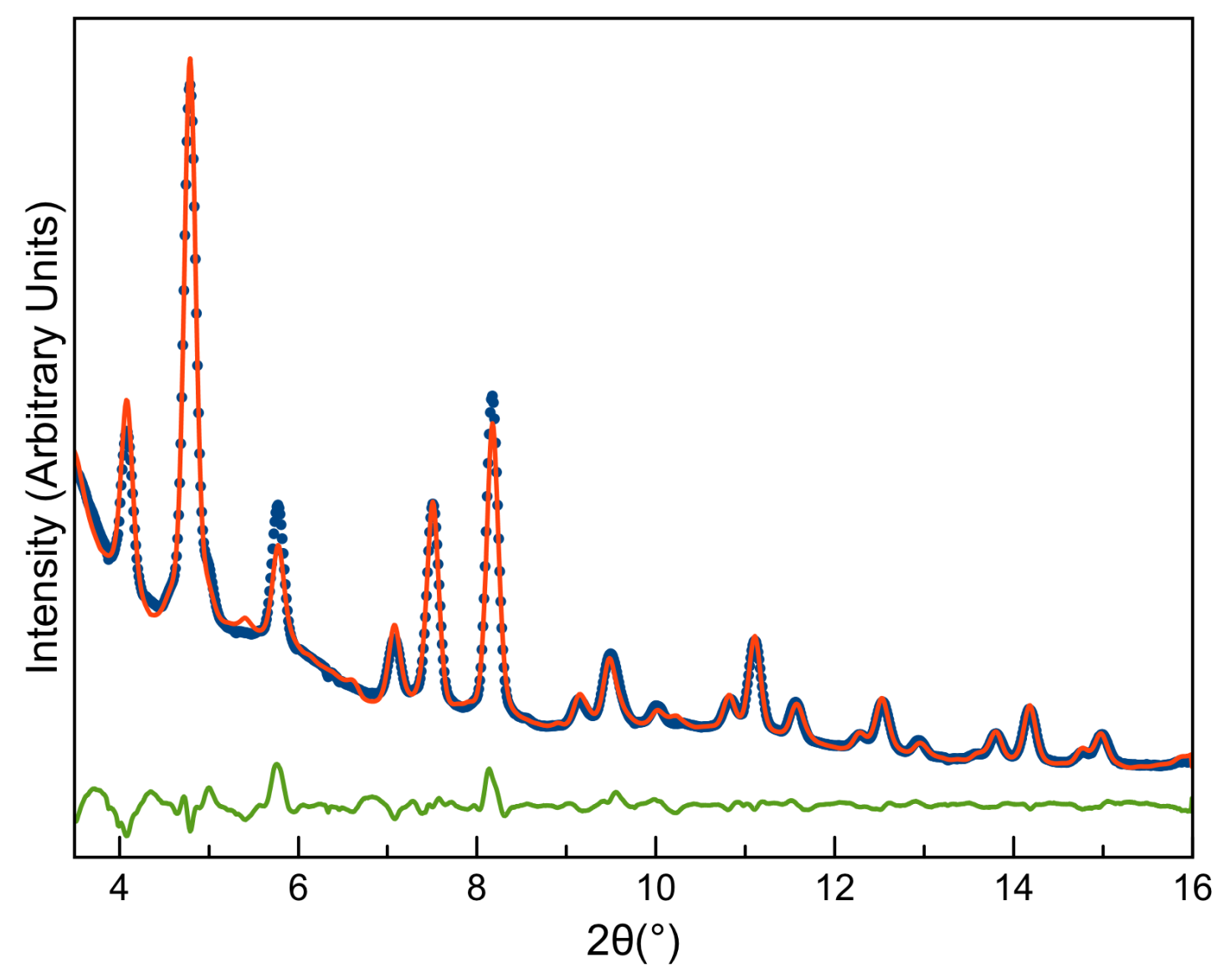

Figure S5. Powder XRD pattern (blue dots) of the $7.6 \mathrm{~nm}$ NCs (core size determined by PDF). The red line represents a fit using Rietveld refinement for the structural model that takes the space group $P 4_{3} 2_{2} 2$. The difference curve between the data and the model is shown in green.

Table S2. Refined parameters for the Rietveld refinement of the $7.6 \mathrm{~nm}$ NCs shown in Fig. S4. Space group $P_{4}{ }_{3}{ }_{2} 2$.

\begin{tabular}{|c|c|}
\hline Bragg R factor & $5.2 \%$ \\
\hline Rf factor & $4.5 \%$ \\
\hline $\mathrm{a}$ & $8.381 \AA$ \\
\hline $\mathrm{c}$ & $8.410 \AA$ \\
\hline Biso Fe & $0.114 \AA^{-2}$ \\
\hline Instrument Displacement & -0.0006 \\
\hline $\mathrm{Y}$ & 0.067 \\
\hline $\mathrm{IG}$ & 0.013 \\
\hline Crystallite diameter $(\mathrm{nm})$ & $7.5 \mathrm{~nm}$ \\
\hline
\end{tabular}


Table S3. Refined parameters from Rietveld refinement of the $7.6 \mathrm{~nm}$ NCs for the four different structural models that take the space groups $F d-3 m, P 4_{3} 3_{2}, P 4_{3} 2_{1} 2, P 4_{1} 2_{1} 2$.

\begin{tabular}{|c|c|c|c|c|}
\hline Space Group & $F d-3 m$ & $\mathrm{P}_{3} 3_{2}$ & $P 4{ }_{3}{ }_{1} 2$ & $P 4{ }_{1}{ }_{1} 2$ \\
\hline Bragg R factor & $3.9 \%$ & $6.7 \%$ & $5.2 \%$ & $6.7 \%$ \\
\hline Rf factor & $3.1 \%$ & $7.2 \%$ & $4.5 \%$ & $7.2 \%$ \\
\hline A & $8.389 \AA$ & $8.391 \AA$ & $8.381 \AA$ & $8.386 \AA$ \\
\hline $\mathrm{C}$ & -- & -- & $8.410 \AA$ & $25.204 \AA$ \\
\hline Biso Fe & $\begin{array}{l}0.598 \AA^{-2}(\mathrm{Fe} 1) \\
0.545 \AA^{-2}(\mathrm{Fe} 2)\end{array}$ & $0.090 \AA^{-2}$ & $0.114 \AA^{-2}$ & $0.542 \AA^{-2}$ \\
\hline Instrument Displacement & -0.0025 & 0.0002 & -0.0006 & -0.0010 \\
\hline $\mathrm{Y}^{\mathrm{T}}$ & 0.034 & 0.061 & 0.067 & 0.036 \\
\hline $\mathrm{IG}$ & 0.018 & 0.014 & 0.013 & 0.017 \\
\hline Crystallite diameter (nm) & $7.5 \mathrm{~nm}$ & $7.4 \mathrm{~nm}$ & $7.5 \mathrm{~nm}$ & $7.5 \mathrm{~nm}$ \\
\hline
\end{tabular}




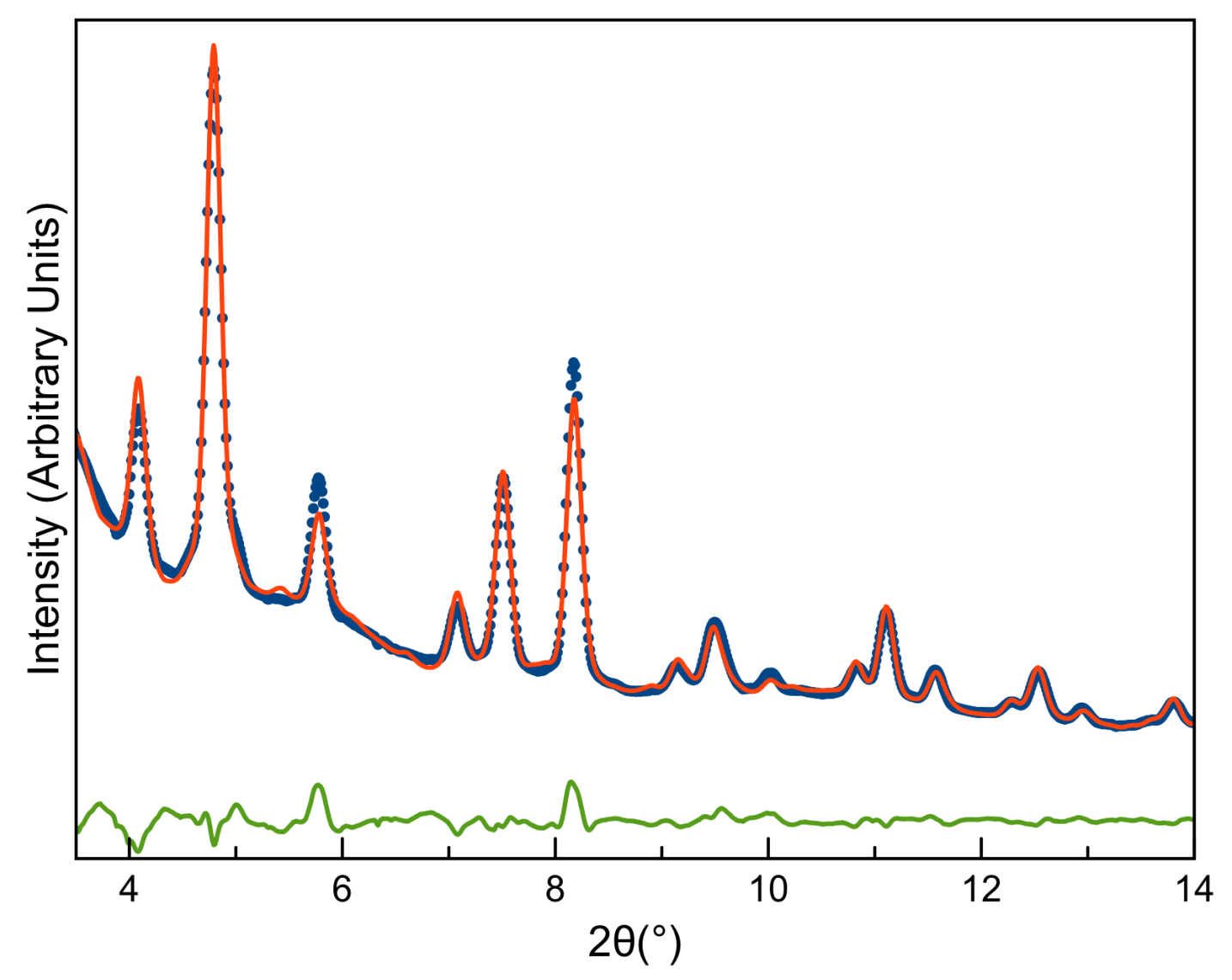

Figure S6. Powder XRD pattern (blue dots) of the $7.4 \mathrm{~nm}$ NCs (core size determined by PDF). The red line represents the fit using Rietveld refinement for the structural model that takes the space group $P 4_{3} 2_{1} 2$. The difference curve between the data and the model is shown in green.

Table S4. Refined parameters for the Rietveld refinement of the $7.4 \mathrm{~nm}$ NCs shown in Fig S5.

\begin{tabular}{|c|c|}
\hline Bragg R factor & $6.2 \%$ \\
\hline Rf factor & $4.7 \%$ \\
\hline A & $8.379 \AA$ \\
\hline C & $8.398 \AA$ \\
\hline Biso Fe & $0.162 \AA^{-2}$ \\
\hline Instrument Displacement & -0.0016 \\
\hline $\mathrm{Y}$ & 0.061 \\
\hline IG & 0.016 \\
\hline Crystallite diameter $(\mathrm{nm})$ & $7.1 \mathrm{~nm}$ \\
\hline
\end{tabular}




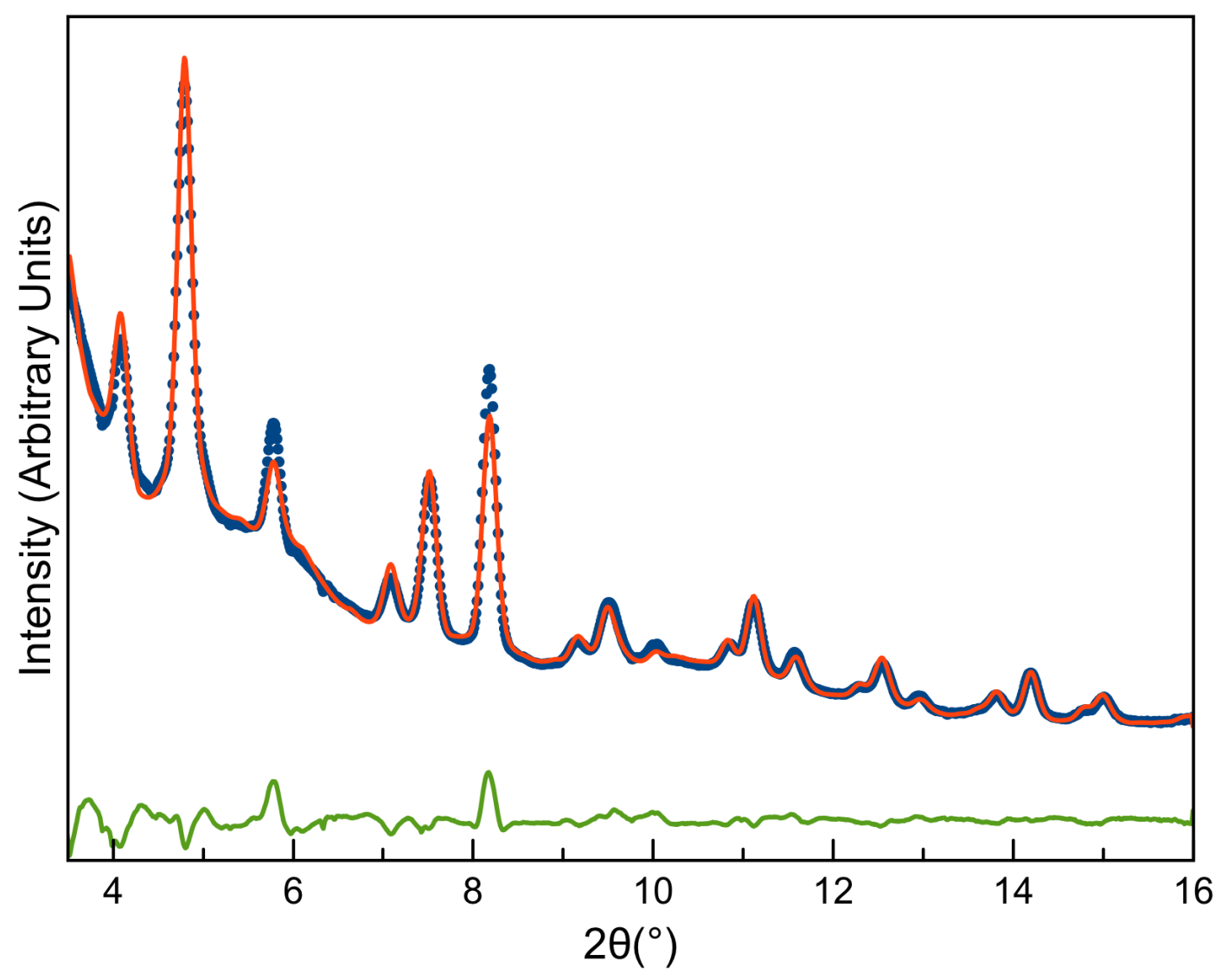

Figure S7. Powder XRD pattern (blue dots) of the $6.9 \mathrm{~nm}$ NCs (core size determined by PDF). The red line represents the fit using Rietveld refinement for the structural model that takes the space group $P 4_{3} 2_{1} 2$. The difference curve between the data and the model is shown in green.

Table S5. Refined parameters for the Rietveld refinement of the $6.9 \mathrm{~nm}$ NCs shown in Fig. S6.

\begin{tabular}{|c|c|}
\hline Bragg R factor & $7.7 \%$ \\
\hline Rf factor & $6.2 \%$ \\
\hline $\mathrm{A}$ & $8.370 \AA$ \\
\hline $\mathrm{C}$ & $8.401 \AA$ \\
\hline Biso Fe & $0.0677 \AA^{-2}$ \\
\hline Instrument Displacement & -0.0019 \\
\hline $\mathrm{Y}$ & 0.060 \\
\hline $\mathrm{IG}$ & 0.022 \\
\hline Crystallite diameter $(\mathrm{nm})$ & $6.3 \mathrm{~nm}$ \\
\hline
\end{tabular}




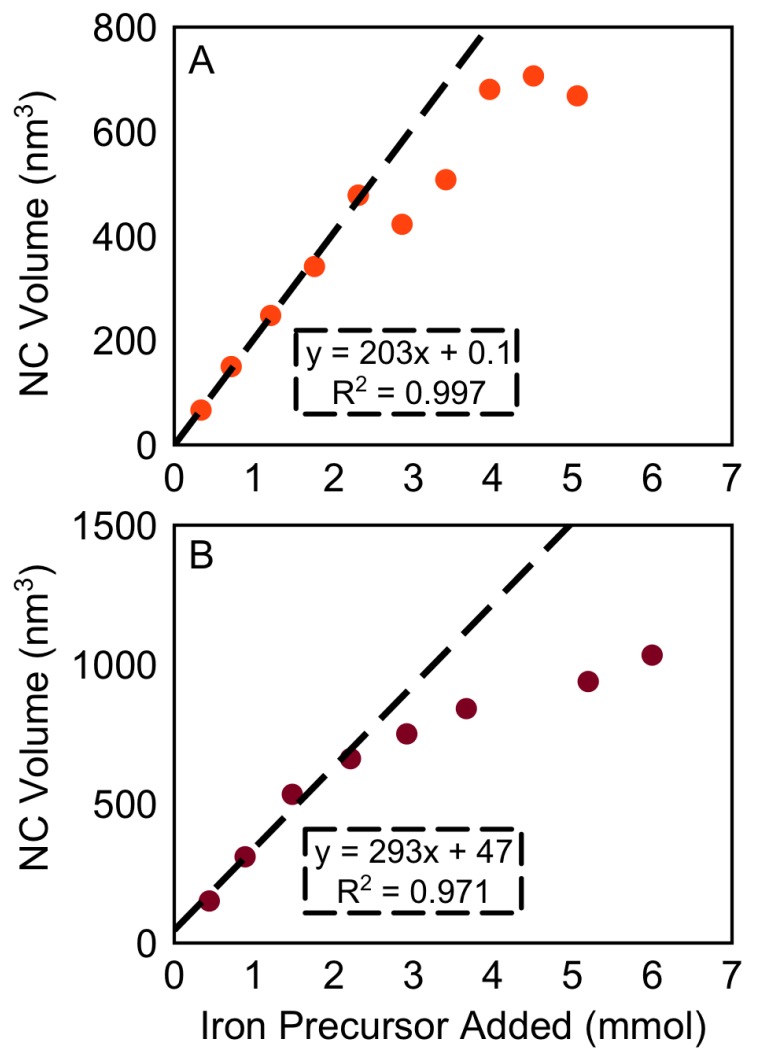

Figure S8. Growth curves for two NC syntheses generated by plotting the NC volume as increased precursor is added to the reaction flask. Dashed lines and regression information are for the initial linear growth behavior. 

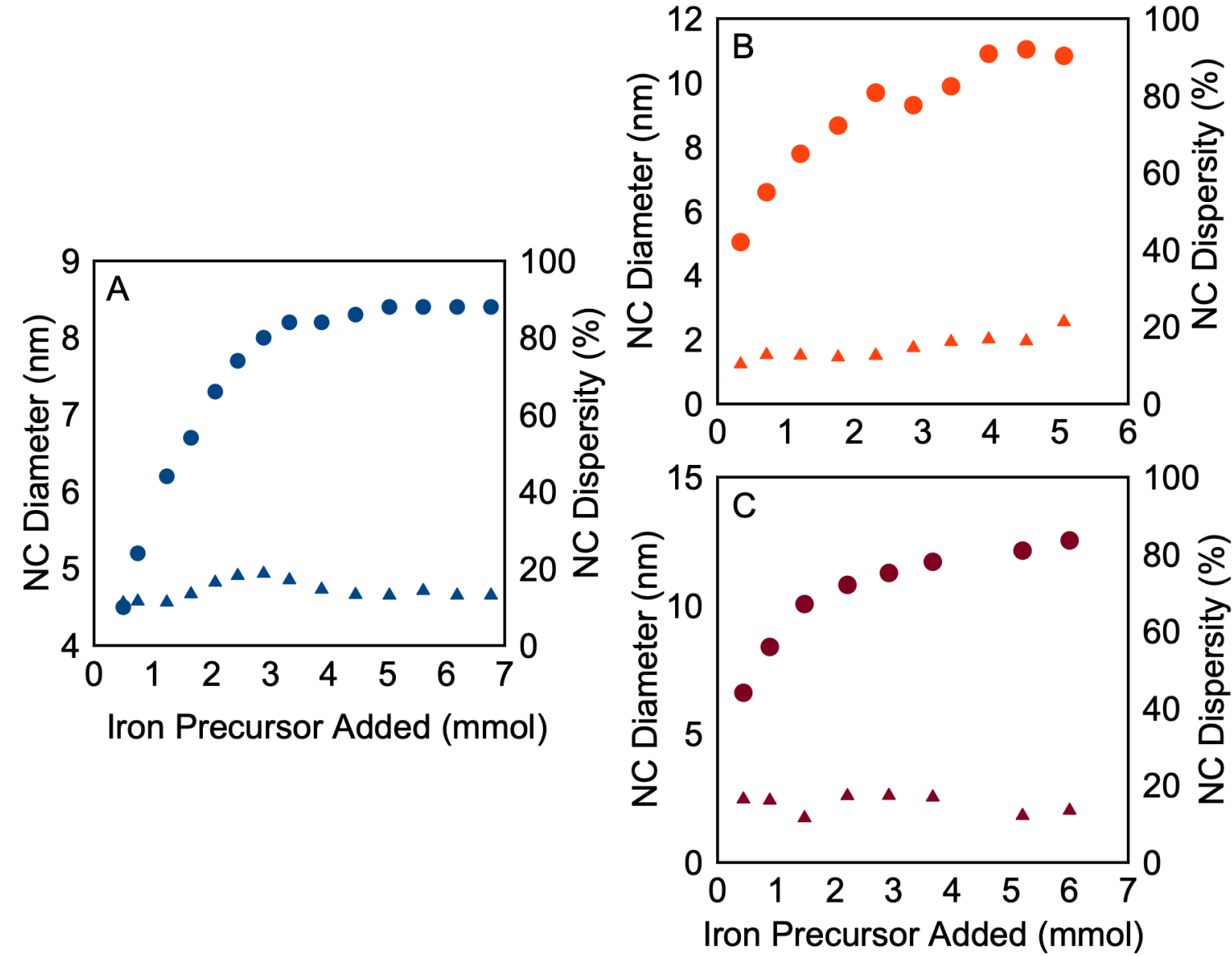

Figure S9. Shows growth curves plotted as NC diameter and relative percentage of polydispersity versus the amount of precursor added to the reaction. (A) Corresponds to the data presented in Figure 4A, (B) corresponds to the data presented in Figure S8A and (C) corresponds to the data presented in Figure S8B.

\section{Discussion of Figure $S 9$}

The size at which the rate of NC growth changes is different for the three different trials of this experiment (Figure S8). This is likely due to small differences in the nucleation which is affected by many variables including drop size during the stages of addition and moisture content of the solvents. 


\section{Distances in Spinel Iron Oxide}

Before any modeling occurs, the PDFs can be analyzed model free by comparing peaks in the PDF that correspond to different atomic distances in the data. Table S7 has a list of common bond pairs at low $\mathrm{r}$ distances in spinel iron oxide.

Table S6. Select bond distances in low $\mathrm{r}$ region for spinel iron oxide that takes the space group $F d-3 m .^{2}$

\begin{tabular}{cc}
\hline Bond pair & $\begin{array}{c}\text { Distance } \\
(\AA)\end{array}$ \\
\hline Fe-O Td & 1.87 \\
Fe-O Oh & 2.06 \\
Fe-Fe Oh & 2.97 \\
FeOh - FeTd & 3.48 \\
FeTd - O & 3.49 \\
FeTd-FeTd & 3.64 \\
FeOh - O & 3.67 \\
\hline
\end{tabular}

\section{Refinement of PDF Data}

Data were refined with a spinel iron oxide model taking the space group $P 4_{3} 2_{1} 2^{4}$ using Diffpy-CMI ${ }^{6}$ software. Instrumental resolution was refined using a $\mathrm{CeO}_{2}$ standard with $\mathrm{Q}_{\mathrm{Broad}}$ refined to a value of $0.01259 \AA$ and QDamp refined to a value of $0.03321 \AA$. Parameters refined were: the scale, cell parameters, crystallite size, correlated atomic motion term (delta2), the occupancy of iron cation positions $\mathrm{Fe} 1$ and $\mathrm{Fe} 4,{ }^{4}$ atomic positions and a dampened sine wave ${ }^{7}$ which we used to describe the solvent. For each refinement we obtain an $\mathrm{R}_{\mathrm{W}}$ value, which is the measure of the goodness of fit of the model to the data. Fel is the tetrahedrally coordinated iron position (Wykoff position b) in the structural model that takes the space group $P 4_{3} 2{ }_{1} 2 .{ }^{4} \mathrm{Fe} 4$ is the octahedrally coordinated iron position (Wykoff position a) which would have an occupancy of 0.33 if the NCs are $100 \%$ maghemite phase. ${ }^{4}$ The thermal parameters $\left(\mathrm{B}_{\text {iso }}\right)$ for both iron and oxygen were fixed at values that were refined for the $7.6 \mathrm{~nm}$ NC (Size Refined by PDF). Each 
iron thermal parameter was refined individually while all oxygen thermal parameters were refined together for the $7.6 \mathrm{~nm} \mathrm{NC}$. Parameters for a dampened sine wave ${ }^{7}$ were also refined, which is discussed below along with Equation S1 and initial values used for refinement in Table S11.

Atomic positions for all iron atoms as well as $\mathrm{O} 2$ and $\mathrm{O} 4$ atoms were also refined.The positions of $\mathrm{O} 1$ and $\mathrm{O} 3$ were held constant because the spread in the positions of $\mathrm{O} 1$ and $\mathrm{O} 3$ over all samples was very broad especially for the smallest NC sizes (Figure S13). There were also some Fe-O bond lengths refined that were shorter than $1.5 \AA$ (Figure S28), shorter than is expected to be physically reasonable in an iron oxide structure. The values of $\mathrm{O} 1$ and $\mathrm{O} 3$ were fixed at the average values determined by refining all positions and all thermal parameters (values from Figure S13). Fixing the $\mathrm{O} 1$ and $\mathrm{O} 3$ values at average positions gave shortest $\mathrm{Fe}-\mathrm{O}$ bonds at $1.6 \AA$ (Figure S14 and S15), closer to previously reported bond lengths for vacancy ordered maghemite ${ }^{5}$ which refined shortest bond lengths of $1.64 \AA$. The bond lengths were also more centered around $2 \AA$ without a secondary population of short bonds. The refined bond lengths for the smallest and largest NC size are included in Figure S14 and S15 respectively.

Refinements were performed sequentially for all 16 samples. Each refinement commenced with a short range refinement $(2.7-20 \AA)$ that had no wave parameters refined. Next, a long range refinement (2.7-60 $\AA$ ) was done with no wave parameters refined. This was followed by a long range refinement in which only wave parameters were refined, Finally, a long range refinement with all parameters refined together. When wave parameters were refined during the initial structral refinements we obtained less consistent results. 


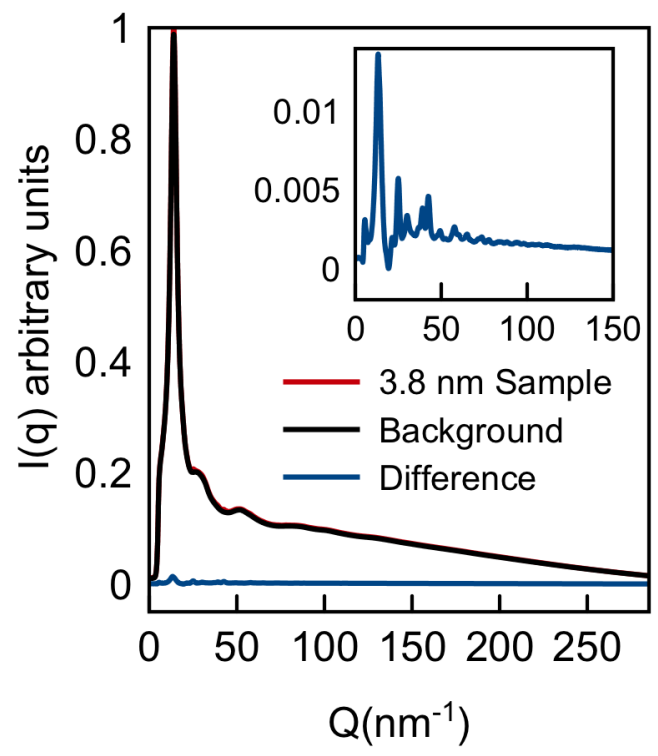

Figure S10. Intensity from X-ray total scattering, I(q), for both the $3.8 \mathrm{~nm}$ sample (core size determined by PDF, red line), the background of oleic acid and oleyl alcohol (black line) and the difference between the sample and the background (blue line). The inset is a blow up of the difference curve (blue).

Table S7. Starting values for the sequential PDF refinement of all 16 samples. Space group $P 4_{3} 2_{12}$

\begin{tabular}{|c|c|}
\hline $\mathrm{a}, \mathrm{b}$ & $8.402 \AA$ \\
\hline $\mathrm{c}$ & $8.305 \AA$ \\
\hline Delta 2 & $2 \AA$ \\
\hline Fe1 occupancy & 0.7 \\
\hline Fe4 occupancy & 0.33 \\
\hline Crystallite Diameter & $40 \AA$ \\
\hline Biso Fe1 & $0.49 \AA^{-2}$ \\
\hline Biso Fe2 & $0.46 \AA^{-2}$ \\
\hline Biso Fe3 & $0.70 \AA^{-2}$ \\
\hline Biso Fe4 & $0.39 \AA^{-2}$ \\
\hline Biso O & $0.9 \AA^{-2}$ \\
\hline
\end{tabular}


Table S8. Starting values for the sequential PDF refinement of all 16 samples. Space group $\mathrm{P}_{3}{ }_{3}{ }_{1} 2$

\begin{tabular}{|c|c|c|c|}
\hline & $\mathrm{x}$ & $\mathrm{y}$ & $\mathrm{z}$ \\
\hline $\mathrm{Fe} 1$ & 0.747 & 0.004 & 0.125 \\
\hline $\mathrm{Fe} 2$ & 0.630 & 0.630 & 0 \\
\hline $\mathrm{Fe} 3$ & 0.371 & 0.867 & 0.982 \\
\hline $\mathrm{Fe} 4$ & 0.132 & 0.132 & 0 \\
\hline $\mathrm{O} 1$ & 0.562 & 0.895 & 0.965 \\
\hline $\mathrm{O} 2$ & 0.119 & 0.377 & -0.005 \\
\hline $\mathrm{O} 3$ & 0.109 & 0.828 & 0.041 \\
\hline $\mathrm{O} 4$ & 0.383 & 0.631 & -0.003 \\
\hline
\end{tabular}

\section{Discussion of Equation $\mathrm{S1}$}

Initial fits showed a residual signal in the difference curve that appeared to be a dampened sine wave. This curve has been shown previously by Zobel et al. (Equation S1) and is due to solvent restructuring around the NPs for dilute NPs in solution. ${ }^{7}$ In Equation $\mathrm{S} 1, A$ is the amplitude, $\lambda$ is the wavelength and $\varphi$ is the phase shift. The value for the effective dampening $\left(\sigma_{\text {eff }}\right)$ is $\sigma_{\text {eff }}=\sigma / a$ for $r<r_{0}$ and $\sigma_{\text {eff }}=\sigma^{*} a$ for $r<r_{0}$ where $a$ is the asymmetry parameter. The variable $r_{0}$ does not correspond to a physical parameter but is used to describe the different dampening behavior of the sine wave. The value of $r_{0}$ was fixed to have an upper bound of $2.7 \AA$ so that the dampening behavior was not inconsistent over the range we are refining $(2.7-60 \AA)$. Not fixing an upper bound to $r_{0}$ led to sharp erroneous peaks in the refined sine wave. The starting values of the refinement were set to values that were reasonable from previous refinements for the data series. Data was fit using Diffpy-CMI ${ }^{6}$ to refine both the structural model and the damped sinusoidal wave (Equation S1).

$$
w(r)=A \sin \left(2 \pi\left(\frac{r}{\lambda}-\varphi\right)\right) e^{-\left(\frac{\left(r-r_{0}\right)}{2 \sigma_{e f f}}\right)^{2}}
$$


Table S9. Starting values for the PDF refinement for Equation S1.

\begin{tabular}{|c|c|}
\hline$A$ & $0.5 \AA$ \\
\hline$\lambda$ & $4 \AA$ \\
\hline$\varphi$ & $1^{\circ}$ \\
\hline$r_{0}$ & $1 \AA$ \\
\hline$\sigma$ & $4 \AA$ \\
\hline$a$ & 1 \\
\hline
\end{tabular}

Table S10. Values from PDF refinements for 4 select sizes using the structural model taking the space group $P 4_{3} 2_{1} 2$.

\begin{tabular}{|c|c|c|c|c|}
\hline $\begin{array}{c}\text { Crystallite } \\
\text { Diameter }\end{array}$ & $30 \AA$ & $49 \AA$ & $54 \AA$ & $74 \AA$ \\
\hline $\mathrm{R}_{\mathrm{W}}$ & 0.41 & 0.16 & 0.20 & 0.12 \\
\hline $\mathrm{a}, \mathrm{b}$ & $8.337 \AA$ & $8.388 \AA$ & $8.409 \AA$ & $8.376 \AA$ \\
\hline $\mathrm{c}$ & $8.372 \AA$ & $8.331 \AA$ & $8.353 \AA$ & $8.376 \AA$ \\
\hline Delta 2 & $7.0 \AA$ & $3.8 \AA$ & $2.6 \AA$ & $3.6 \AA$ \\
\hline Fe1 occupancy & 0.79 & 0.84 & 0.88 & 0.98 \\
\hline Fe4 occupancy & 0.33 & 0.69 & 0.40 & 0.63 \\
\hline $\mathrm{Fe} 1 \mathrm{x}$ & 0.747 & 0.748 & 0.744 & 0.747 \\
\hline $\mathrm{Fe} 1 \mathrm{y}$ & 0.993 & 0.998 & 0.994 & 0.996 \\
\hline $\mathrm{Fe} 1 \mathrm{z}$ & 0.119 & 0.123 & 0.117 & 0.118 \\
\hline $\mathrm{Fe} 2 \mathrm{x}=\mathrm{y}$ & 0.640 & 0.633 & 0.635 & 0.632 \\
\hline $\mathrm{Fe} 3 \mathrm{x}$ & 0.374 & 0.374 & 0.375 & 0.374 \\
\hline $\mathrm{Fe} 3 \mathrm{y}$ & 0.872 & 0.870 & 0.868 & 0.870 \\
\hline $\mathrm{Fe} 3 \mathrm{z}$ & 0.980 & 0.990 & 0.991 & 0.989 \\
\hline $\mathrm{Fe} 4 \mathrm{x}=\mathrm{y}$ & 0.121 & 0.126 & 0.132 & 0.128 \\
\hline $\mathrm{O} 2 \mathrm{x}$ & 0.110 & 0.120 & 0.120 & 0.122 \\
\hline $\mathrm{O} 2 \mathrm{y}$ & 0.384 & 0.370 & 0.367 & 0.372 \\
\hline $\mathrm{O} 2 \mathrm{z}$ & 1.001 & 0.994 & 1.000 & 0.996 \\
\hline $\mathrm{O} 4 \mathrm{x}$ & 0.385 & 0.380 & 0.380 & 0.379 \\
\hline $\mathrm{O} 4 \mathrm{y}$ & 0.634 & 0.622 & 0.624 & 0.628 \\
\hline $\mathrm{O} 4 \mathrm{z}$ & 0.999 & 0.003 & 0.997 & 0.996 \\
\hline$A$ & $1.2 \AA$ & $1.8 \AA$ & $0.8 \AA$ & $1.0 \AA$ \\
\hline$\lambda$ & $2100 \AA$ & $2400 \AA$ & $0.37 \AA$ & $240 \AA$ \\
\hline$\varphi^{\mathrm{o}}$ & $5.4^{\circ}$ & $4.8^{\circ}$ & $5.0^{\circ}$ & $64^{\circ}$ \\
\hline$r_{0}$ & $0.8 \AA$ & $1.0 \AA$ & $1.0 \AA$ & $0.1 \AA$ \\
\hline$\sigma$ & $-28 \AA$ & $-82 \AA$ & $2.7 \AA$ & $-15 \AA$ \\
\hline$a$ & 4.8 & 7.6 & 5.4 & 4.0 \\
\hline
\end{tabular}



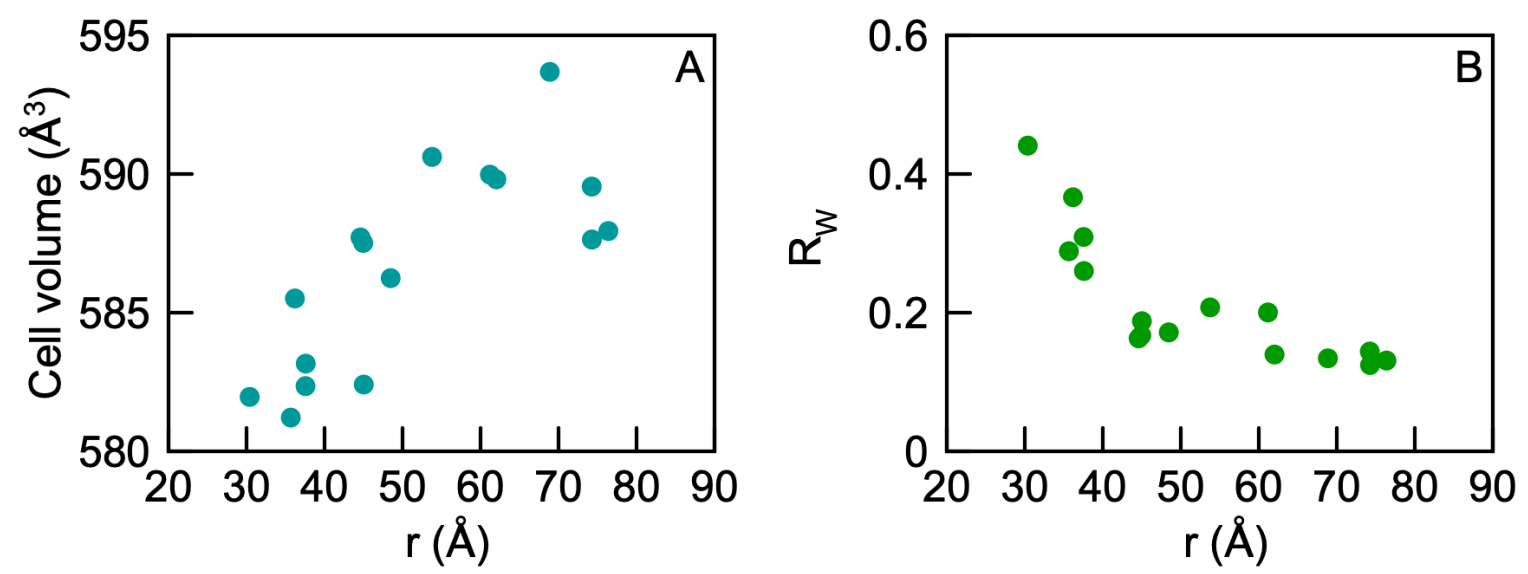

Figure S11. Refined values of the cell volume and $\mathrm{R}_{\mathrm{W}}$ for the entire size series plotted against the refined crystallite size by PDF. Space group $P_{4} 2_{1} 2$
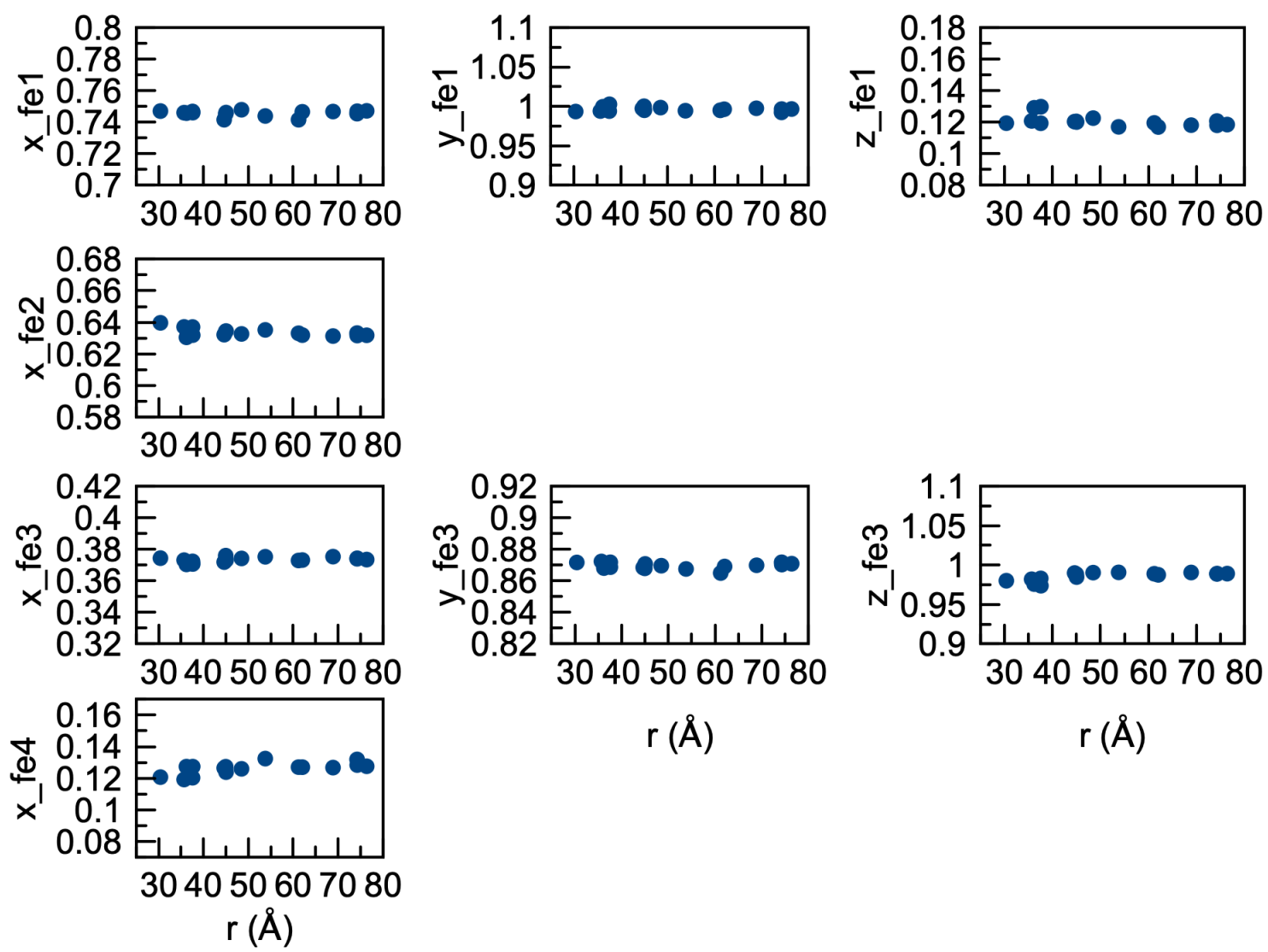

$r(\AA)$

Figure S12. Refined atomic positions for all of the iron positions for the entire size series plotted against the refined crystallite size by PDF. Space group $P 4_{3} 2_{12}$ 

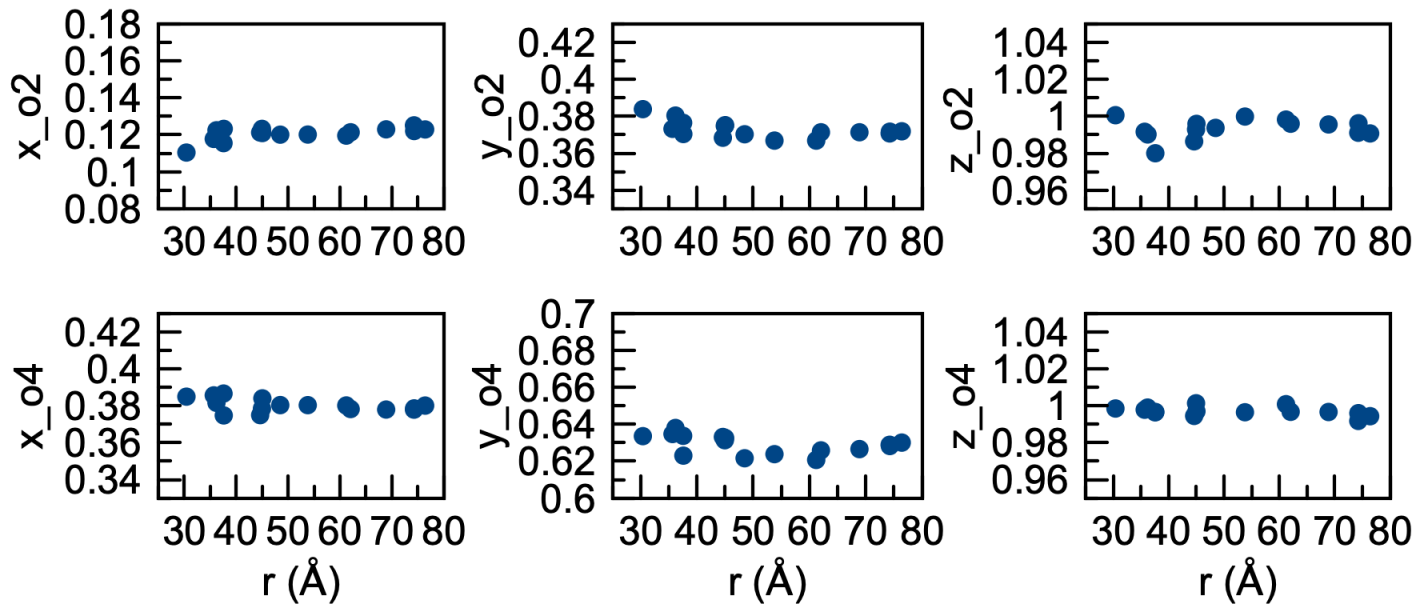

Figure $\mathrm{S} 13$. Refined atomic positions for oxygen positions, $\mathrm{O} 2$ and $\mathrm{O} 4$, for the entire size series plotted against the refined crystallite size by PDF. Space group $P 4_{3} 2_{1} 2$
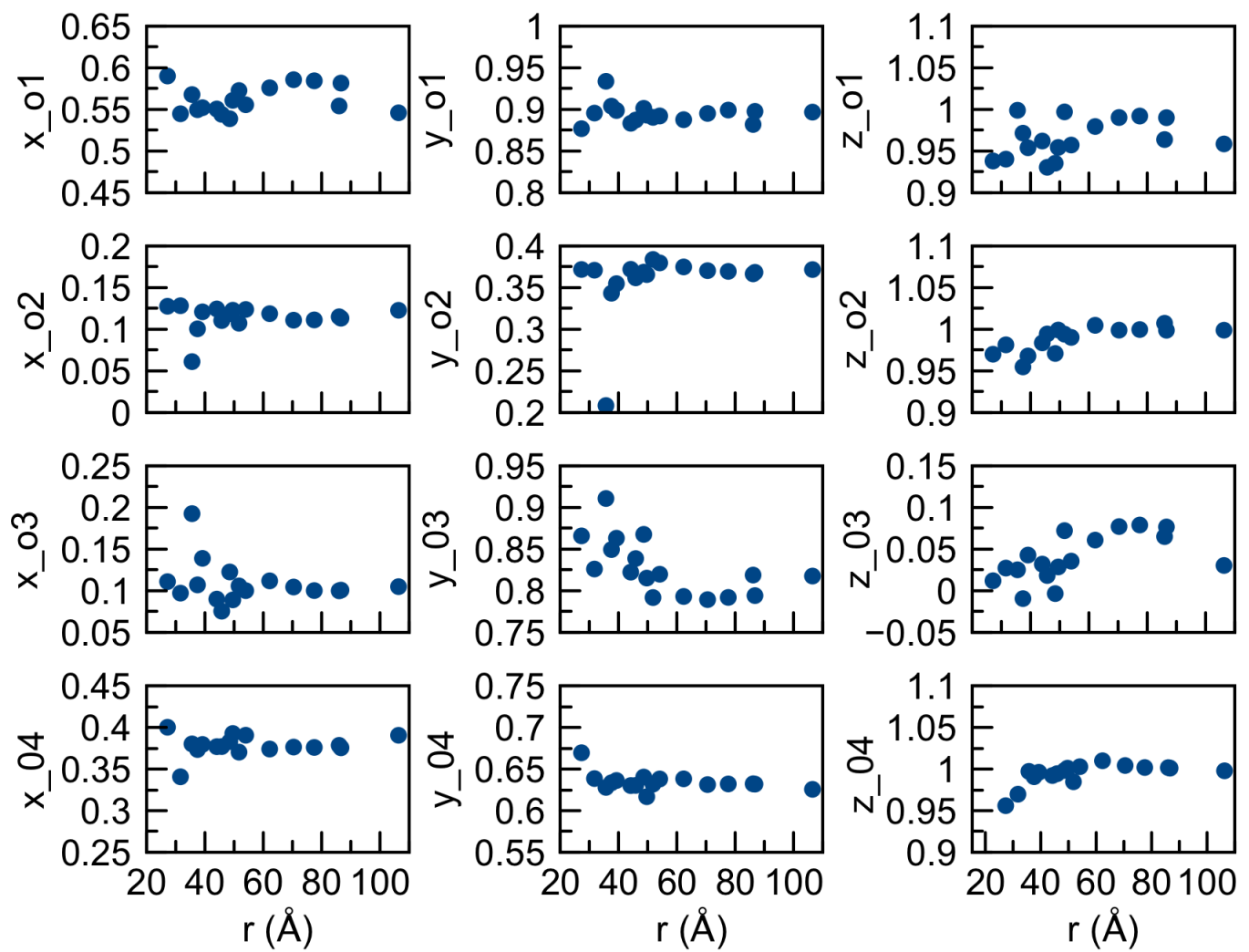

Figure S14. Refined atomic positions for all oxygen positions before the final refinement where the positions of $\mathrm{O} 1$ and $\mathrm{O} 3$ were fixed at the average values. 


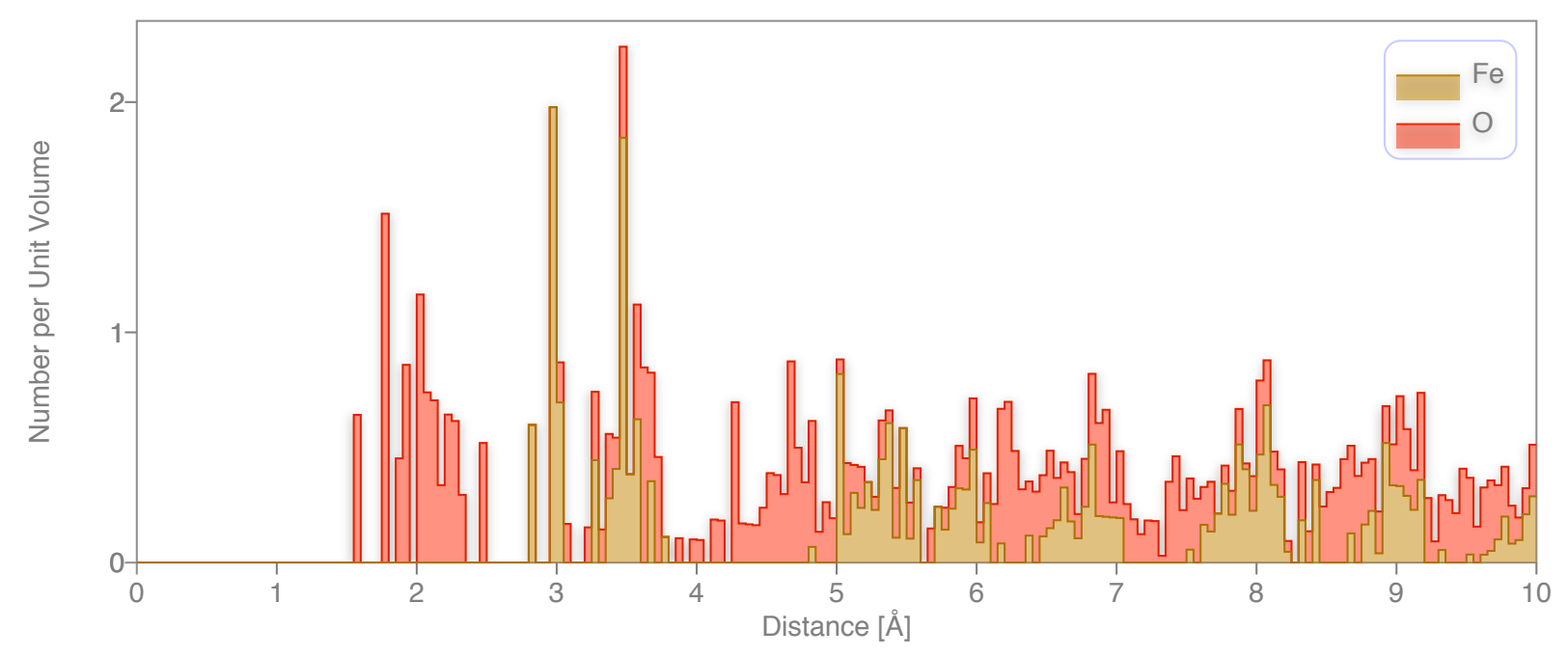

Figure S15. Bond distance histogram from the final refinement for the sample with a diameter of $3.0 \mathrm{~nm}$ NCs (core size determined by PDF).

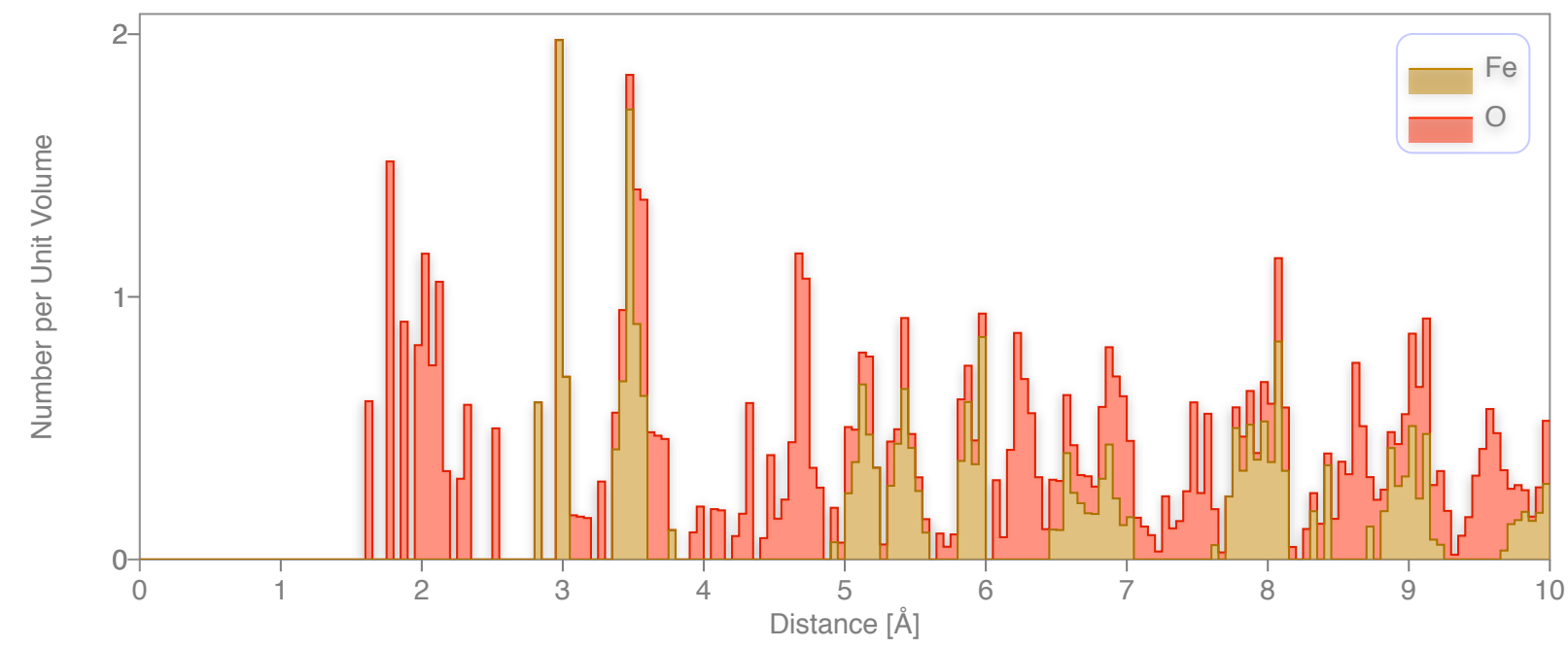

Figure S16. Bond distance histogram from the final refinement for the sample with a diameter of $7.4 \mathrm{~nm}$ NCs (core size determined by PDF). 


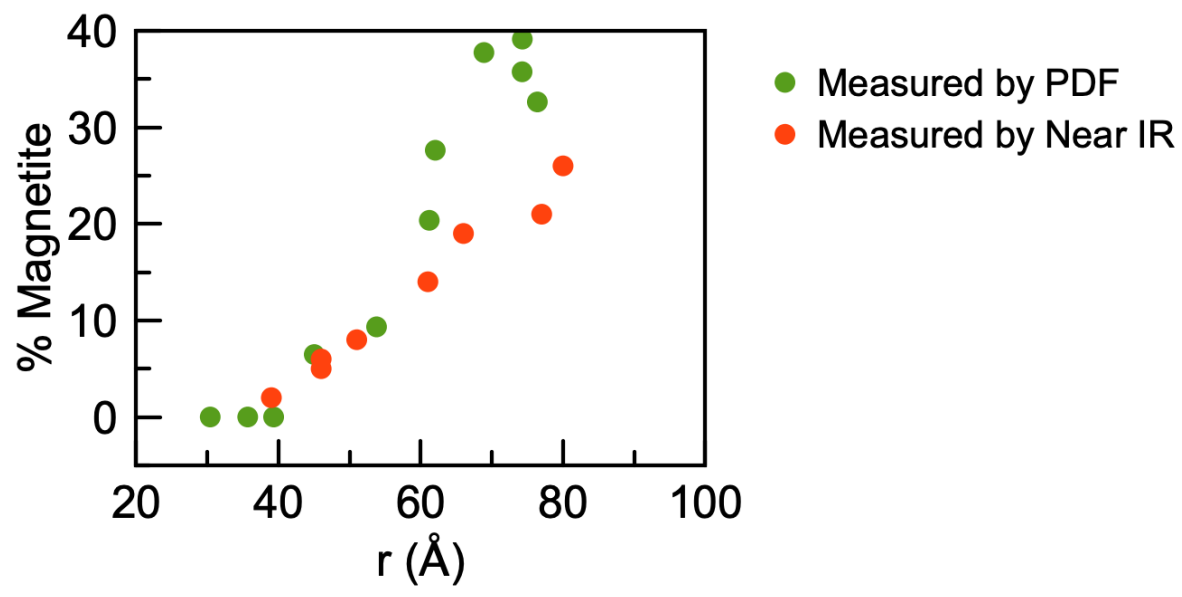

Figure S17. Percent magnetite of samples that were aged at least three weeks before analysis. The percent magnetite for the green dots was determined by refining PDF data and the orange dots were determined by Near-IR spectroscopy for a series of nanocrystals produced by the same synthesis. ${ }^{8}$ All Near-IR spectra were normalized to the isobestic point at $400 \mathrm{~nm}$. The absorbance at $1450 \mathrm{~nm}$ was then compared to the absorbance from a a commercial magnetite sample to determine the percent magnetite.

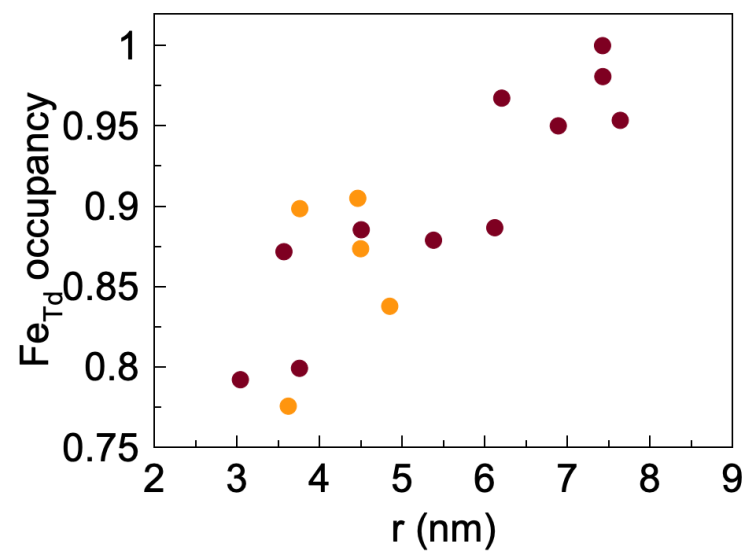

Figure S18. Fe $\mathbf{T d}_{\mathbf{T}}$ site occupancy versus the refined NC diameter using the structural model that takes the space group $\mathrm{P}_{3} 2_{1} 2$. The orange dots represent NCs that were synthesized 5 days before data collection. The brown dots represent NCs that were synthesized from 4 months to 3 weeks before data collection.

\section{Discussion Figure S18}

In Figure S18, the values for refined $\mathbf{F e}_{\text {Td }}$ Occupancy for NCs synthesized 5 days before data collection are scattered among the values for $\mathbf{F e}_{\mathbf{T d}}$ Occupancy for NCs that are synthesized at 
least 3 weeks before data collection. Therefore, since there is no clear trend in $\mathrm{Td}$ occupancy over time there does not seem to be a dependence of $\mathbf{F e}_{\text {Td }}$ occupancy due to oxidation.

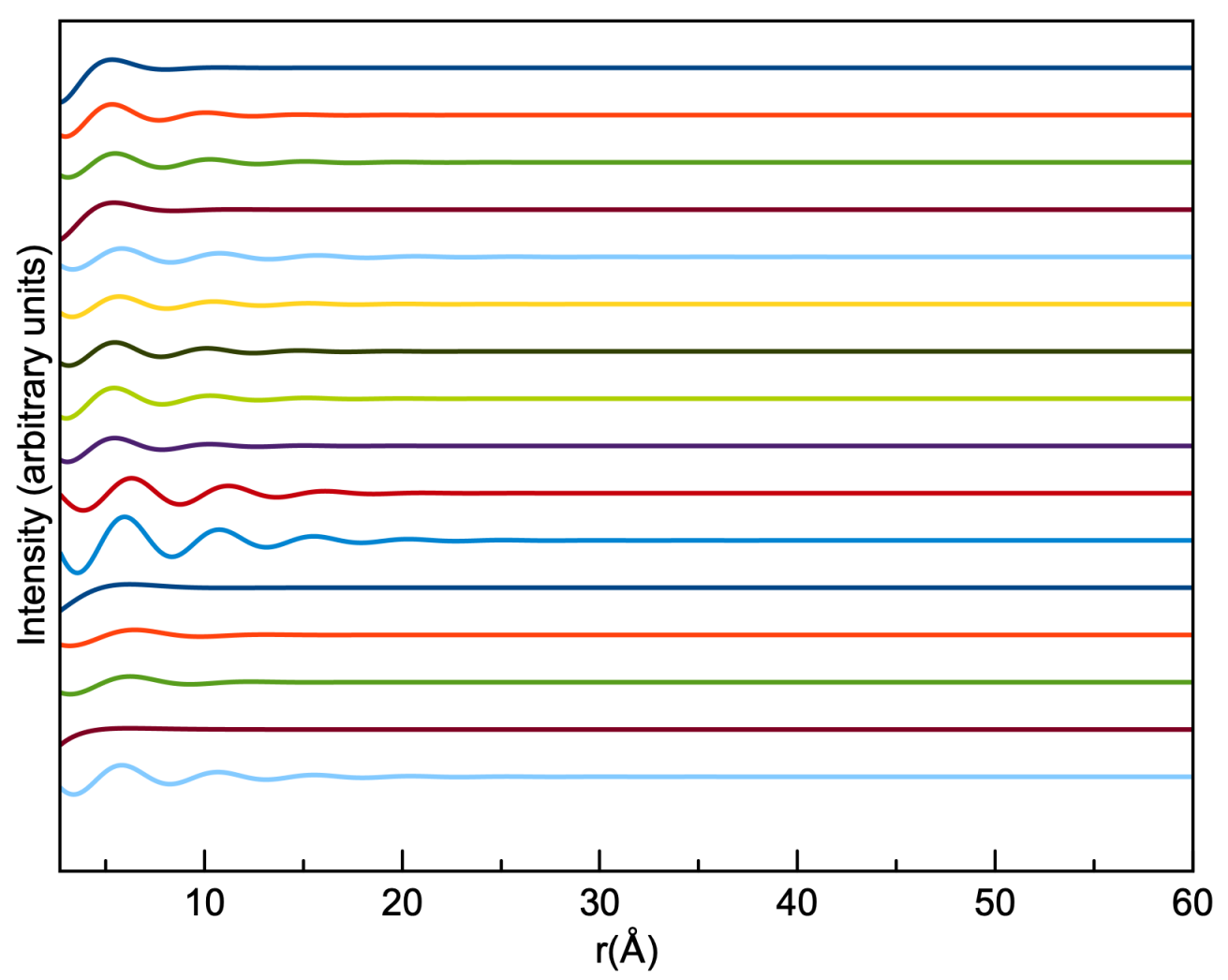

Figure S19. Waves refined for all samples using the structural model that takes the space group $P_{4} 2_{2} 2$. The smallest $\mathrm{NC}$ is at the top and the largest $\mathrm{NC}$ is on the bottom of the figure in the same order as Table S1. 


\section{PDF Refinement Using Other Crystallographic Models}

\section{Refinements with Fd-3m}

Table S11. Starting parameters for refinement of PDF data using the structural model that takes the space group $F d-3 m$.

\begin{tabular}{|c|c|}
\hline $\mathrm{a}$ & $8.397 \AA$ \\
\hline Delta 2 & $2 \AA$ \\
\hline Fe1 occupancy & 0.7 \\
\hline Fe2 occupancy & 0.83 \\
\hline Crystallite Diameter & $40 \AA$ \\
\hline Biso Fe1 & $0.39 \AA^{-2}$ \\
\hline Biso Fe2 & $0.55 \AA^{-2}$ \\
\hline Biso O & $0.8 \AA^{-2}$ \\
\hline$A$ & $0.5 \AA$ \\
\hline$\lambda$ & $4 \AA$ \\
\hline$\varphi$ & $1^{\circ}$ \\
\hline$r_{0}$ & $1 \AA$ \\
\hline$\sigma$ & $4 \AA$ \\
\hline$a$ & 1 \\
\hline
\end{tabular}

Table S12. Starting positions for refinement of PDF data using the structural model that takes the space group $F d-3 m$.

\begin{tabular}{|c|c|c|c|}
\hline & $\mathrm{x}$ & $\mathrm{y}$ & $\mathrm{z}$ \\
\hline $\mathrm{Fe} 1$ & 0.125 & 0.125 & 0.125 \\
\hline $\mathrm{Fe} 2$ & 0.5 & 0.5 & 0.5 \\
\hline $\mathrm{O} 1$ & 0.255 & 0.255 & 0.255 \\
\hline
\end{tabular}


Table S13. Refined values for 4 select sizes using model using the structural model that takes the space group $F d-3 m$.

\begin{tabular}{|c|c|c|c|c|}
\hline $\begin{array}{c}\text { Crystallite } \\
\text { Diameter }\end{array}$ & $29 \AA$ & $45 \AA$ & $49 \AA$ & $64 \AA$ \\
\hline $\mathrm{R}_{\mathrm{W}}$ & 0.48 & 0.25 & 0.32 & 0.22 \\
\hline $\mathrm{a}$ & $8.362 \AA$ & $8.371 \AA$ & $8.389 \AA$ & $8.405 \AA$ \\
\hline Delta 2 & $6.9 \AA$ & $1.6 \AA$ & $1.1 \mathrm{E}-05 \AA$ & $1.7 \AA$ \\
\hline Fe1 occupancy & 1.00 & 1.00 & 1.00 & 1.00 \\
\hline Fe4 occupancy & 0.93 & 1.00 & 0.98 & 1.00 \\
\hline $\mathrm{O} 1 \mathrm{x}=\mathrm{y}=\mathrm{z}$ & 0.264 & 0.260 & 0.260 & 0.260 \\
\hline$A$ & $7200 \AA$ & $0.3 \AA$ & $0.4 \AA$ & $0.0 \AA$ \\
\hline$\lambda$ & $4.4 \AA$ & $4.7 \AA$ & $4.9 \AA$ & $4.3 \AA$ \\
\hline$\varphi$ & $1.0^{\circ}$ & $1.0^{\circ}$ & $1.1{ }^{\circ}$ & $0.8^{\circ}$ \\
\hline$r_{0}$ & $-70 \AA$ & $-4.2 \AA$ & $2.7 \AA$ & $0.5 \AA$ \\
\hline$\sigma$ & $6.8 \AA$ & $9.0 \AA$ & $4.3 \AA$ & $-4.2 \mathrm{E}+11 \AA$ \\
\hline$a$ & 1.7 & 0.7 & 1.0 & $4.0 \mathrm{E}+09$ \\
\hline
\end{tabular}



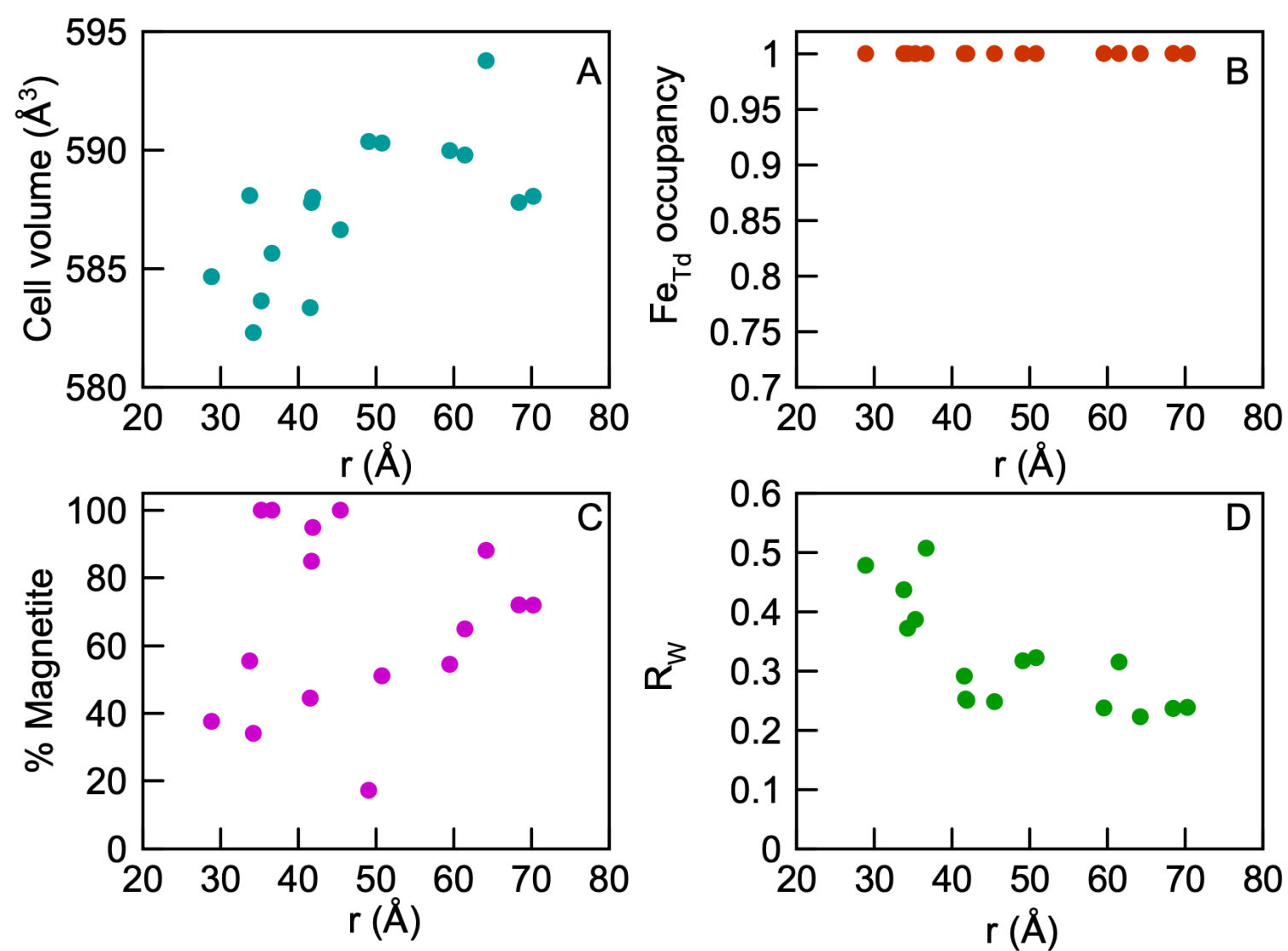

Figure S20. Refined parameters as a function of refined diameter for all 16 samples refined by PDF with (A) cell volume, (B) vacancies on tetrahedrally coordinated iron sites, (C) \% magnetite and D) $R_{W}$ factor expressing the goodness of fit at each size. Space group $F d-3 m$ 


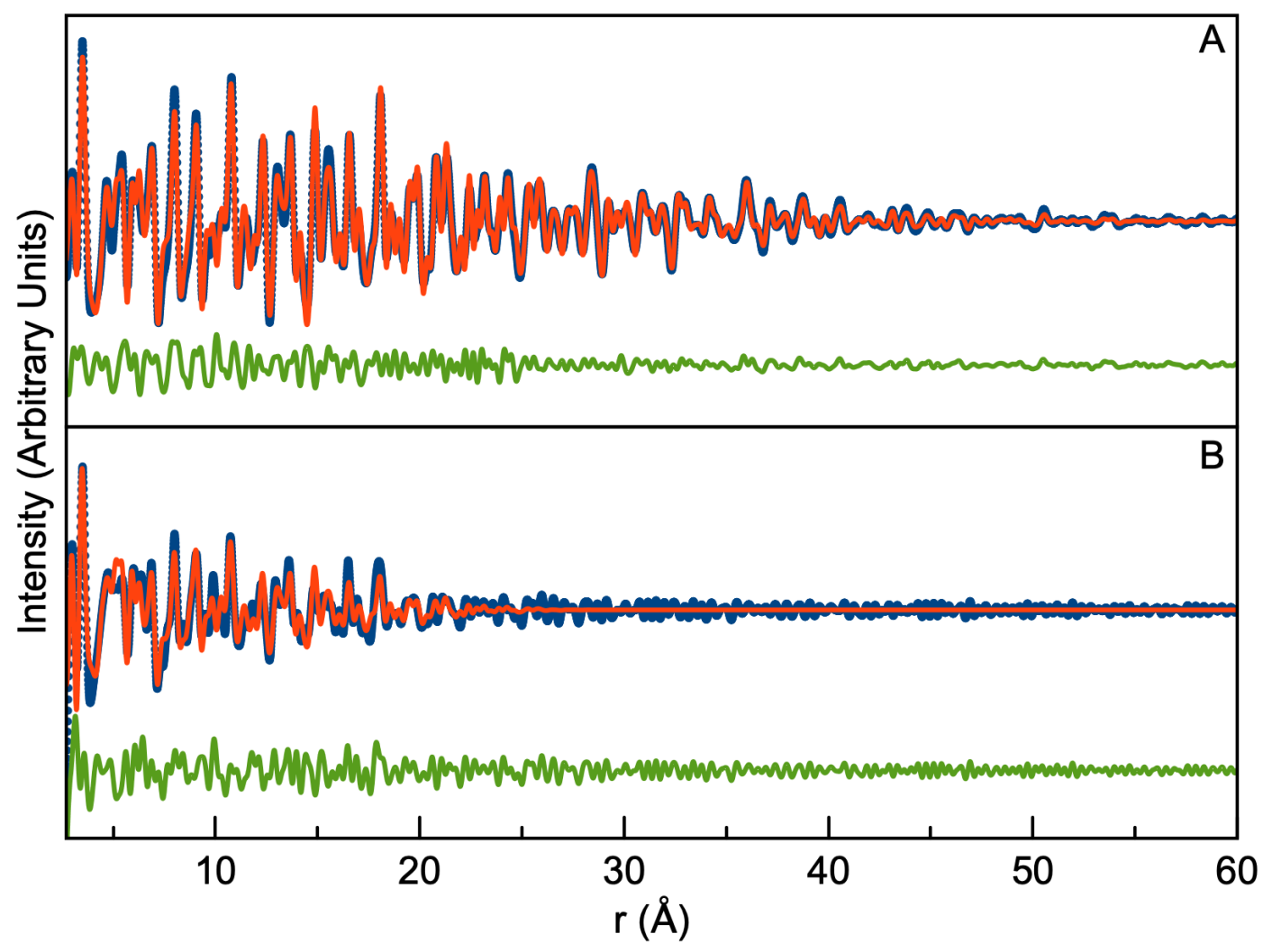

Figure S21. Fits and difference curves for data of large and small NCs using the structural model that takes the space group $F d-3 m$. Data for (A) $7.4 \mathrm{~nm}$ NCs and (B) $3.0 \mathrm{~nm} \mathrm{NCs}$ are shown as blue dots. The red line is the fit to the model and the green line is the difference between the model and the data. 


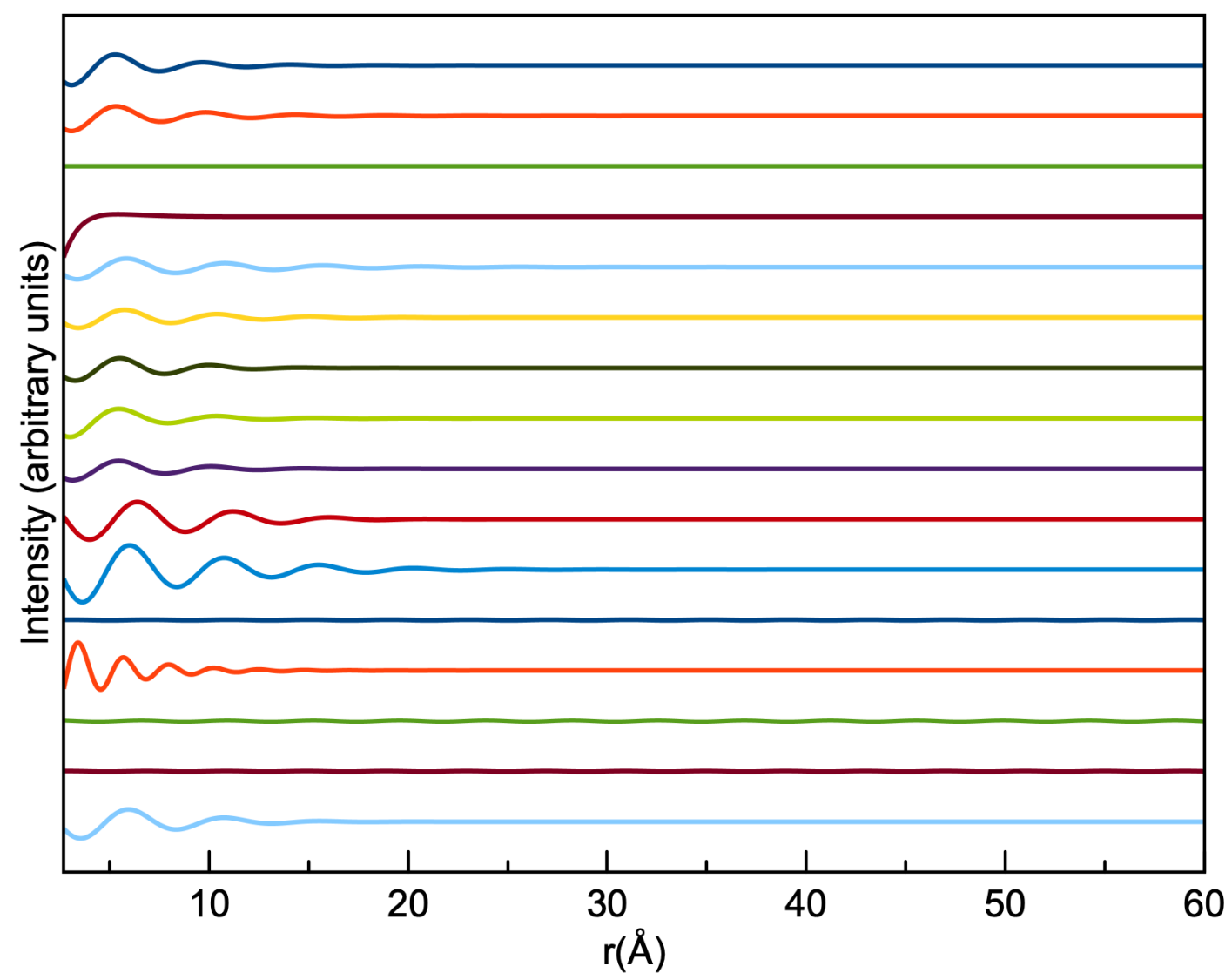

Figure S22. Waves refined for all samples with the smallest NC at the top and the largest NC on the bottom of the figure in the same order as Table S1. Space group $F d-3 m$

\section{Refinements with $\mathrm{P}_{3} 3_{2}$}

Table S14. Starting parameters for refinement of PDF data using the structural model that takes the space group $P 4_{3} 3_{2}$.

\begin{tabular}{|c|c|}
\hline $\mathrm{a}$ & $8.347 \AA$ \\
\hline Delta 2 & $2 \AA$ \\
\hline Fe1 occupancy & 0.8 \\
\hline Fe3 occupancy & 0.8 \\
\hline Crystallite Diameter & $40 \AA$ \\
\hline Biso Fe & $0.54 \AA^{-2}$ \\
\hline Biso O & $0.8 \AA^{-2}$ \\
\hline$A$ & $0.5 \AA$ \\
\hline$\lambda$ & $4 \AA$ \\
\hline$\varphi$ & $1^{\circ}$ \\
\hline$r 0$ & $1 \AA$ \\
\hline$\sigma$ & $4 \AA$ \\
\hline$a$ & 1 \\
\hline
\end{tabular}


Table S15. Starting positions for refinement of PDF data using the structural model that takes the space group $\mathrm{P}_{3} 3_{2}$.

\begin{tabular}{|c|c|c|c|}
\hline & $\mathrm{x}$ & $\mathrm{y}$ & $\mathrm{z}$ \\
\hline $\mathrm{Fe} 1$ & 0.992 & 0.992 & 0.992 \\
\hline $\mathrm{Fe} 2$ & 0.865 & 0.615 & 0.875 \\
\hline $\mathrm{Fe} 3$ & 0.375 & 0.125 & 0.875 \\
\hline $\mathrm{O} 1$ & 0.861 & 0.861 & 0.861 \\
\hline $\mathrm{O} 2$ & 0.372 & 0.377 & 0.876 \\
\hline
\end{tabular}

Table S16. Refined values for four select sizes using the structural model that takes the space group $\mathrm{P}_{4} 3_{2}$.

\begin{tabular}{|c|c|c|c|c|}
\hline $\begin{array}{c}\text { Crystallite } \\
\text { Diameter }\end{array}$ & $28 \AA$ & $47 \AA$ & $54 \AA$ & $73 \AA$ \\
\hline $\mathrm{R}_{\mathrm{w}}$ & 0.48 & 0.25 & 0.25 & 0.22 \\
\hline $\mathrm{a}$ & $8.373 \AA$ & $8.375 \AA$ & $8.392 \AA$ & $8.379 \AA$ \\
\hline Delta 2 & $3.5 \AA$ & $4.0 \AA$ & $3.2 \AA$ & $4.3 \AA$ \\
\hline $\begin{array}{c}\mathrm{Fe} 1 \\
\text { occupancy }\end{array}$ & 0.93 & 1.00 & 1.00 & 1.00 \\
\hline $\begin{array}{c}\mathrm{Fe} 3 \\
\text { occupancy }\end{array}$ & 0.33 & 0.81 & 0.41 & 0.45 \\
\hline $\begin{array}{c}\mathrm{Fe} 2 \mathrm{x} \\
(\mathrm{y}+1 / 2, \\
\mathrm{y}+1 / 4,7 / 8)\end{array}$ & 0.872 & 0.876 & 0.869 & 0.873 \\
\hline $\mathrm{O} 2 \mathrm{x}$ & 0.366 & 0.368 & 0.358 & 0.371 \\
\hline $\mathrm{O} 2 \mathrm{y}$ & 0.360 & 0.363 & 0.388 & 0.355 \\
\hline $\mathrm{O} 2 \mathrm{z}$ & 0.898 & 0.893 & 0.870 & 0.888 \\
\hline$A$ & $12000 \AA$ & $4800 \AA$ & $0.4 \AA$ & $720 \AA$ \\
\hline$\lambda$ & $4.5 \AA$ & $4.8 \AA$ & $4.9 \AA$ & $7.2 \AA$ \\
\hline$\varphi$ & $0.91^{\mathrm{o}}$ & $0.96^{\mathrm{o}}$ & $1.0^{\circ}$ & $0.71^{\mathrm{o}}$ \\
\hline$r_{0}$ & $-100 \AA$ & $-82 \AA$ & $2.1 \AA$ & $-56 \AA$ \\
\hline$\sigma$ & $7.9 \AA$ & $7.4 \AA$ & $4.9 \AA$ & $6.6 \AA$ \\
\hline$a$ & 2.0 & 1.9 & 0.92 & 1.6 \\
\hline
\end{tabular}



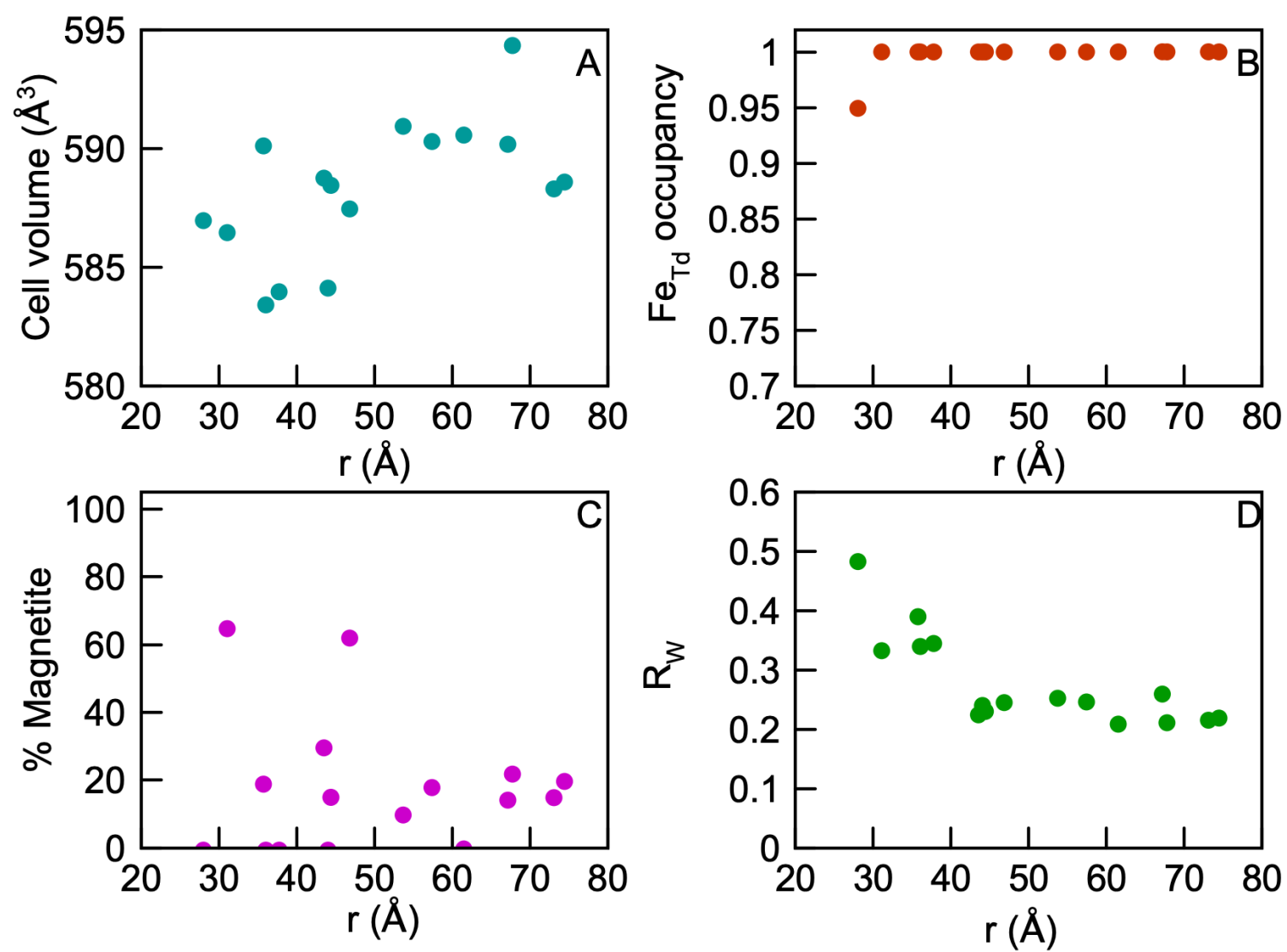

Figure S23. Refined parameters as a function of diameter for 16 samples refined by PDF using the structural model that takes the space group $P_{4} 3_{2}$. A) Cell volume, B) vacancies on tetrahedrally coordinated iron sites, C) \% magnetite and D) $\mathrm{R}_{W}$ factor expressing the goodness of fit at each size. 


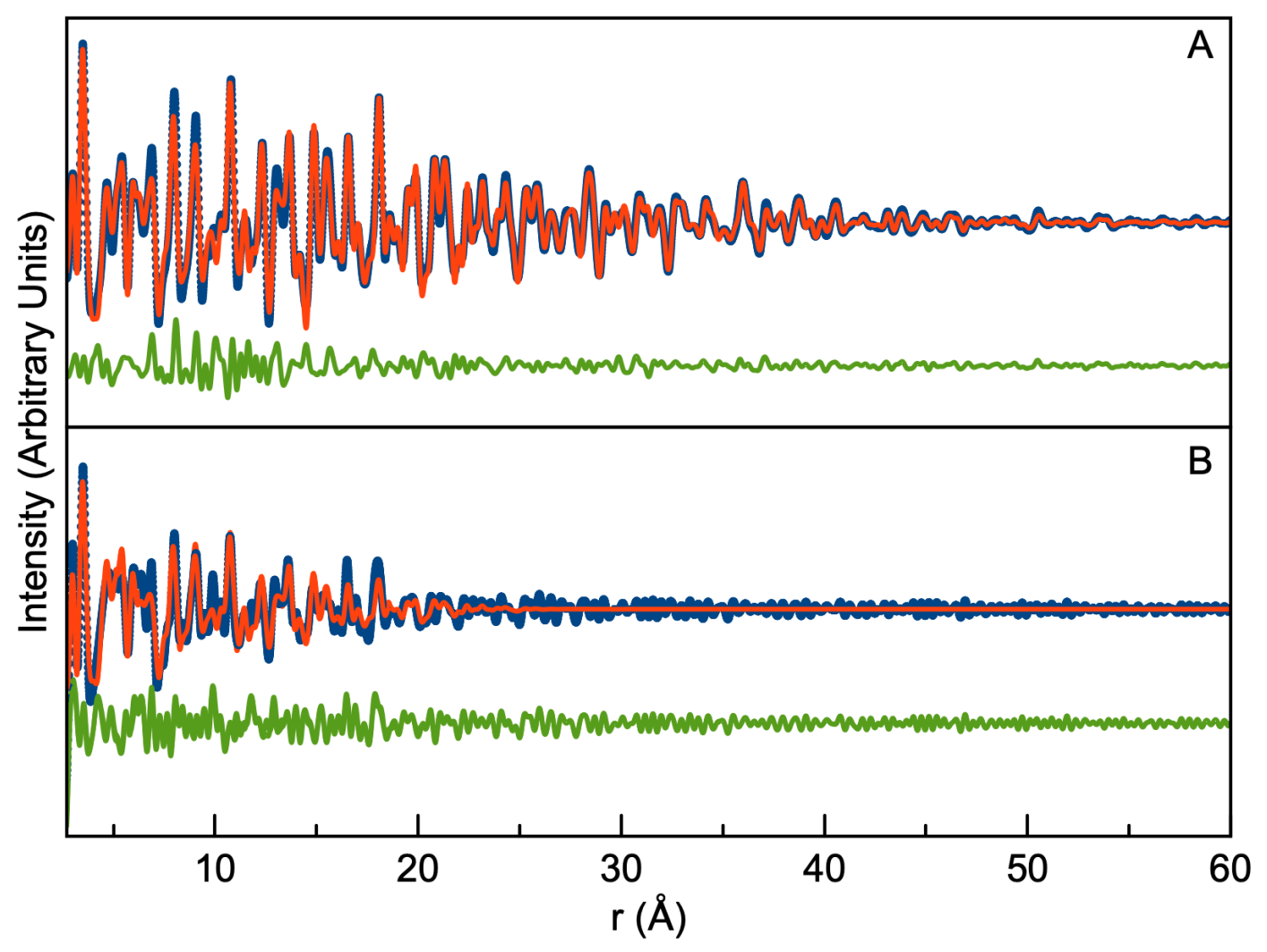

Figure S24. Fits and difference curves for scattering data collected for large and small NCs using the structural model that takes the space group $P_{3} 3_{2}$. Data for (A) $7.6 \mathrm{~nm} \mathrm{NCs}$ and (B) $3.0 \mathrm{~nm}$ $\mathrm{NCs}$ are shown in blue dots. The red line shows the fit to the model and the green line is the difference between the model and the data. 


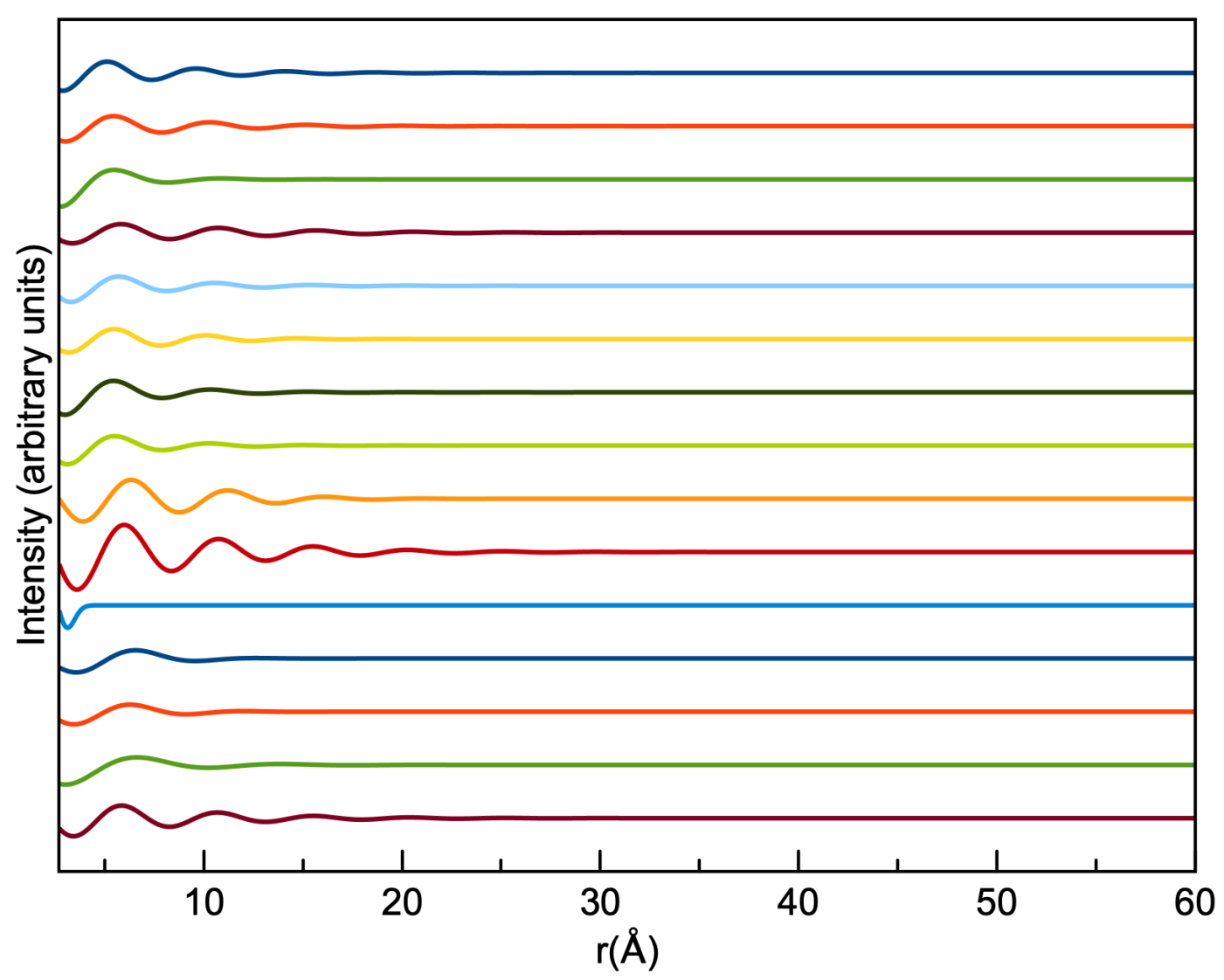

Figure S25. Waves refined for all samples using the structural model that takes the space group $P_{3} 3_{2}$ with the smallest $\mathrm{NC}$ at the top and the largest $\mathrm{NC}$ on the bottom of the figure in the same order as Table S1. 
Table S17. Starting parameters for refinement of PDF data using the structural model that takes the space group $P 4_{1} 2_{1} 2$.

\begin{tabular}{|c|c|}
\hline $\mathrm{a}, \mathrm{b}$ & $8.332 \AA$ \\
\hline $\mathrm{c}$ & $25.113 \AA$ \\
\hline Delta 2 & $2 \AA$ \\
\hline Fe1 occupancy & 0.8 \\
\hline Fe2 occupancy & 0.8 \\
\hline Fe3 occupancy & 0.8 \\
\hline Crystallite Diameter & $40 \AA$ \\
\hline Biso Fe & $0.5 \AA^{-2}$ \\
\hline Biso O & $0.8 \AA^{-2}$ \\
\hline$A$ & $0.5 \AA$ \\
\hline$\lambda$ & $4 \AA$ \\
\hline$\varphi$ & $1^{\circ}$ \\
\hline$r_{0}$ & $1 \AA$ \\
\hline$\sigma$ & $4 \AA$ \\
\hline$a$ & 1 \\
\hline
\end{tabular}

Table S18. Starting positions for refinement of PDF data using the structural model that takes the space group $P 4{ }_{1}{ }_{1} 2$.

\begin{tabular}{|c|c|c|c|}
\hline & $\mathrm{x}$ & $\mathrm{y}$ & $\mathrm{z}$ \\
\hline $\mathrm{Fe} 1$ & 0.751 & 0.997 & 0.0417 \\
\hline $\mathrm{Fe} 2$ & 0.751 & 0.997 & 0.375 \\
\hline $\mathrm{Fe} 3$ & 0.751 & 0.997 & 0.7084 \\
\hline $\mathrm{Fe} 4$ & 0.621 & 0.621 & 0 \\
\hline $\mathrm{Fe} 5$ & 0.621 & 0.621 & 0.3333 \\
\hline $\mathrm{Fe} 6$ & 0.369 & 0.869 & 0.998 \\
\hline $\mathrm{Fe} 7$ & 0.369 & 0.869 & 0.3313 \\
\hline $\mathrm{Fe} 8$ & 0.369 & 0.869 & 0.6647 \\
\hline $\mathrm{Fe} 9$ & 0.128 & 0.128 & 0 \\
\hline $\mathrm{Fe} 10$ & 0.128 & 0.128 & 0.3333 \\
\hline $\mathrm{O} 1$ & 0.612 & 0.881 & 0 \\
\hline O2 & 0.612 & 0.881 & 0.333 \\
\hline $\mathrm{O} 3$ & 0.612 & 0.881 & 0.667 \\
\hline O4 & 0.11 & 0.317 & 0.003 \\
\hline $\mathrm{O} 5$ & 0.11 & 0.317 & 0.336 \\
\hline $\mathrm{O} 6$ & 0.11 & 0.317 & 0.67 \\
\hline O7 & 0.133 & 0.853 & 0 \\
\hline O8 & 0.133 & 0.853 & 0.333 \\
\hline O9 & 0.133 & 0.853 & 0.67 \\
\hline O10 & 0.385 & 0.626 & 0.006 \\
\hline O11 & 0.385 & 0.626 & 0.339 \\
\hline O12 & 0.385 & 0.626 & 0.673 \\
\hline
\end{tabular}


Table S19. Refined values for four select sizes using the structural model that takes the space group $P 4{ }_{1}{ }_{1} 2$.

\begin{tabular}{|c|c|c|c|c|}
\hline $\begin{array}{l}\text { Crystallite } \\
\text { Diameter }\end{array}$ & 31 & 43 & 47 & 76 \\
\hline $\mathrm{R}_{\mathrm{W}}$ & 0.29 & 0.14 & 0.19 & 0.08 \\
\hline$a, b$ & $8.316 \AA$ & $8.373 \AA$ & $8.394 \AA$ & $8.387 \AA$ \\
\hline $\mathrm{c}$ & $25.344 \AA$ & $25.110 \AA$ & $25.158 \AA$ & $25.048 \AA$ \\
\hline Delta 2 & $1.9 \AA$ & $2.0 \AA$ & $2.0 \AA$ & $2.1 \AA$ \\
\hline $\begin{array}{c}\text { Fe } 1 \\
\text { occupancy }\end{array}$ & 0.60 & 0.63 & 0.56 & 0.91 \\
\hline $\begin{array}{c}\text { Fe } 2 \\
\text { occupancy }\end{array}$ & 0.78 & 0.82 & 0.89 & 1.00 \\
\hline $\begin{array}{c}\text { Fe } 3 \\
\text { occupancy }\end{array}$ & 0.51 & 0.60 & 0.69 & 0.75 \\
\hline $\begin{array}{c}\text { Fe } 10 \\
\text { occupancy }\end{array}$ & 0.84 & 0.74 & 0.59 & 0.20 \\
\hline Fel x & 0.749 & 0.760 & 0.758 & 0.748 \\
\hline Fe1 y & 0.973 & 0.997 & 0.006 & 0.994 \\
\hline Fel z & 0.036 & 0.044 & 0.045 & 0.043 \\
\hline Fe2 $x$ & 0.754 & 0.749 & 0.749 & 0.759 \\
\hline $\mathrm{Fe} 2 \mathrm{y}$ & 0.996 & 0.998 & 0.003 & 0.999 \\
\hline $\mathrm{Fe} 2 \mathrm{z}$ & 0.372 & 0.373 & 0.373 & 0.374 \\
\hline $\mathrm{Fe} 3 \mathrm{x}$ & 0.750 & 0.749 & 0.767 & 0.739 \\
\hline $\mathrm{Fe} 3 \mathrm{y}$ & 0.007 & 0.998 & 0.987 & 0.005 \\
\hline $\mathrm{Fe} 3 \mathrm{z}$ & 0.708 & 0.710 & 0.707 & 0.705 \\
\hline $\mathrm{Fe} 4 \mathrm{x}=\mathrm{y}=\mathrm{z}$ & 0.626 & 0.616 & 0.553 & 0.604 \\
\hline Fe5 $x$ & 0.630 & 0.632 & 0.636 & 0.636 \\
\hline Fe5 y & 0.613 & 0.587 & 0.636 & 0.636 \\
\hline $\mathrm{Fe} 5 \mathrm{z}$ & 0.332 & 0.329 & 0.327 & 0.329 \\
\hline Fe6 $x$ & 0.383 & 0.385 & 0.362 & 0.381 \\
\hline Fe6 y & 0.861 & 0.885 & 0.846 & 0.857 \\
\hline Fe6 z & 0.992 & 0.997 & 0.992 & 0.992 \\
\hline $\mathrm{Fe} 7 \mathrm{x}$ & 0.391 & 0.367 & 0.377 & 0.381 \\
\hline $\mathrm{Fe} 7 \mathrm{y}$ & 0.875 & 0.881 & 0.885 & 0.880 \\
\hline $\mathrm{Fe} 7 \mathrm{z}$ & 0.329 & 0.337 & 0.334 & 0.333 \\
\hline $\mathrm{Fe} 8 \mathrm{x}$ & 0.339 & 0.308 & 0.388 & 0.364 \\
\hline Fe8 y & 0.842 & 0.884 & 0.868 & 0.875 \\
\hline
\end{tabular}




\begin{tabular}{|c|c|c|c|c|}
$\mathrm{Fe} 8 \mathrm{z}$ & 0.651 & 0.653 & 0.667 & 0.666 \\
\hline $\mathrm{Fe} 9 \mathrm{x}=\mathrm{y}=\mathrm{z}$ & 0.119 & 0.125 & 0.112 & 0.118 \\
\hline $\mathrm{Fe} 10 \mathrm{x}$ & 0.113 & 0.140 & 0.097 & 0.109 \\
\hline $\mathrm{Fe} 10 \mathrm{y}$ & 0.172 & 0.113 & 0.133 & 0.130 \\
\hline $\mathrm{Fe} 10 \mathrm{z}$ & 0.302 & 0.331 & 0.335 & 0.316 \\
\hline O1 x & 0.634 & 0.630 & 0.530 & 0.625 \\
\hline O1 y & 0.875 & 0.882 & 0.790 & 0.867 \\
\hline O1 z & 0.002 & 0.999 & 0.980 & 0.002 \\
\hline O2 & 0.554 & 0.594 & 0.638 & 0.630 \\
\hline O2 & 0.857 & 0.772 & 0.806 & 0.874 \\
\hline O2 & 0.332 & 0.279 & 0.295 & 0.331 \\
\hline O3 & 0.602 & 0.635 & 0.627 & 0.610 \\
\hline O3 & 0.891 & 0.875 & 0.869 & 0.883 \\
\hline O3 & 0.694 & 0.663 & 0.670 & 0.659 \\
\hline O4 & 0.060 & 0.020 & 0.048 & 0.997 \\
\hline O4 & 0.256 & 0.265 & 0.270 & 0.319 \\
\hline O4 & 0.985 & 0.989 & 0.983 & 0.992 \\
\hline O5 & 0.029 & 0.073 & 0.027 & 0.985 \\
\hline O5 & 0.266 & 0.194 & 0.253 & 0.295 \\
\hline O5 & 0.287 & 0.280 & 0.287 & 0.288 \\
\hline O6 & 0.103 & 0.037 & 0.025 & 0.103 \\
\hline O6 & 0.291 & 0.275 & 0.219 & 0.292 \\
\hline O6 & 0.656 & 0.636 & 0.671 & 0.693 \\
\hline O7 & 0.146 & 0.132 & 0.133 & 0.056 \\
\hline O7 & 0.872 & 0.871 & 0.880 & 0.884 \\
\hline O7 & 0.021 & 0.000 & 0.999 & 0.983 \\
\hline O8 & 0.143 & 0.208 & 0.084 & 0.131 \\
\hline O8 & 0.906 & 0.909 & 0.928 & 0.881 \\
\hline O8 & 0.346 & 0.333 & 0.367 & 0.337 \\
\hline O9 & 0.122 & 0.126 & 0.125 & 0.139 \\
\hline O9 & 0.874 & 0.878 & 0.870 & 0.869 \\
\hline O9 & 0.667 & 0.669 & 0.667 & 0.672 \\
\hline O10 & 0.372 & 0.384 & 0.389 & 0.371 \\
\hline O10 & 0.634 & 0.624 & 0.639 & 0.613 \\
\hline O10 & 0.999 & 0.999 & 0.003 & 0.000 \\
\hline O11 & 0.360 & 0.457 & 0.406 & 0.382 \\
\hline O11 & 0.590 & 0.633 & 0.592 & 0.615 \\
\hline O11 & 0.348 & 0.320 & 0.319 & 0.333 \\
\hline O12 & 0.365 & 0.458 & 0.397 & 0.440 \\
\hline & & & & \\
\hline
\end{tabular}




\begin{tabular}{|c|c|c|c|c|}
\hline 012 & 0.638 & 0.580 & 0.632 & 0.593 \\
\hline $\mathrm{O} 12$ & 0.665 & 0.692 & 0.664 & 0.693 \\
\hline$A$ & $20000 \AA$ & $1300 \AA$ & $4.2 \AA$ & $0.25 \AA$ \\
\hline$\lambda$ & $4.1 \AA$ & $3.6 \AA$ & $28 \AA$ & $3.9 \AA$ \\
\hline$\varphi$ & $1.0^{\circ}$ & $1.1^{\circ}$ & $0.6^{\circ}$ & $1^{\circ}$ \\
\hline$r_{0}$ & $-69 \AA$ & $-29 \AA$ & $2.2 \AA$ & $2.7 \AA$ \\
\hline$\sigma$ & $6.8 \AA$ & $4.7 \AA$ & $1.6 \AA$ & $-0.9 \AA$ \\
\hline$a$ & 1.6 & 1.2 & 0.4 & 2.2 \\
\hline
\end{tabular}
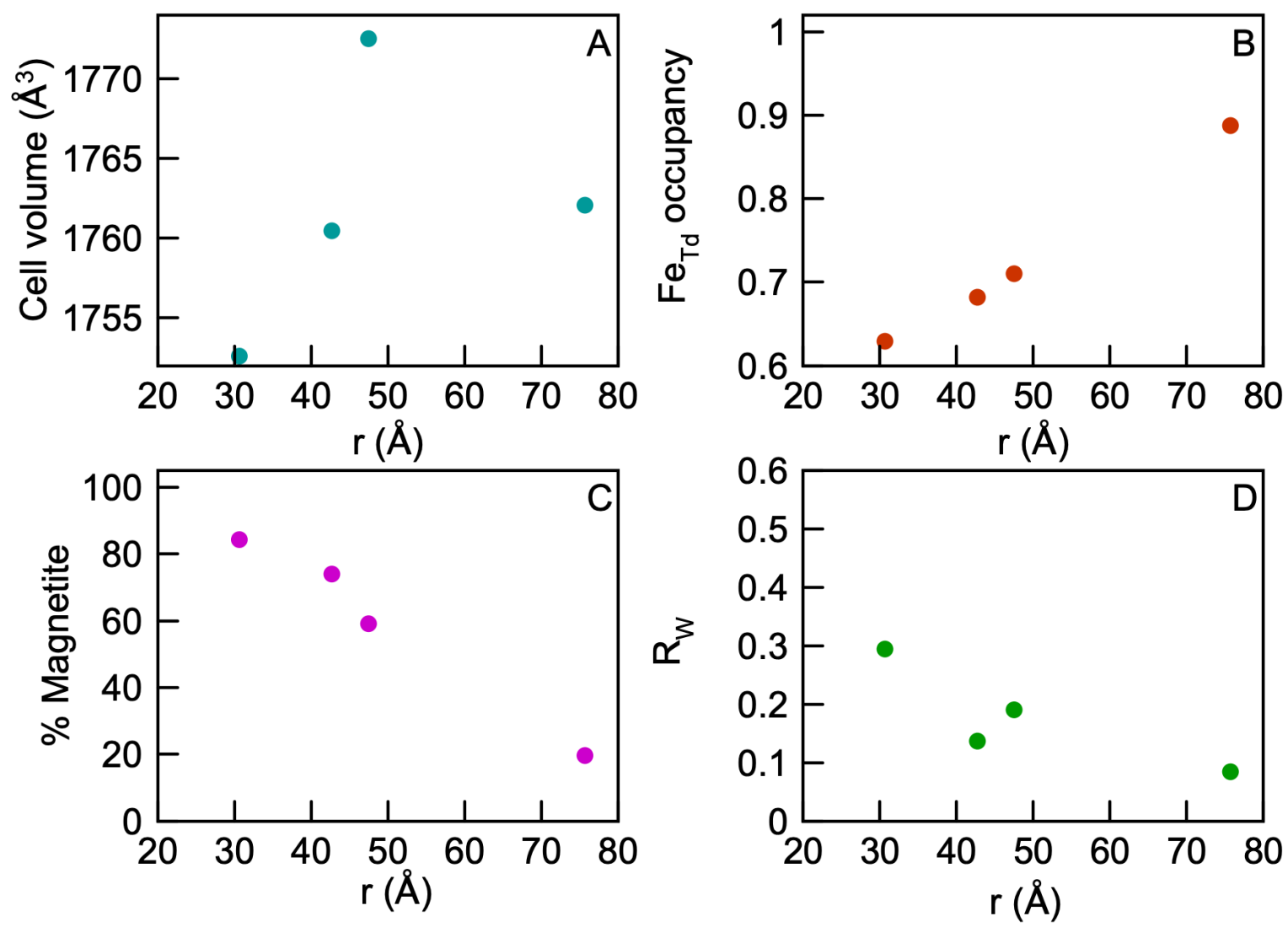

Figure S26. Refined parameters as a function of diameter for 4 samples refined by PDF using the structural model that takes the space group $\mathrm{P}_{4}{ }_{1}{ }_{1} 2$. A) Cell volume, B) vacancies on tetrahedrally coordinated iron sites, C) \% magnetite and D) $\mathrm{R}_{\mathrm{W}}$ factor expressing the goodness of fit at each size. 


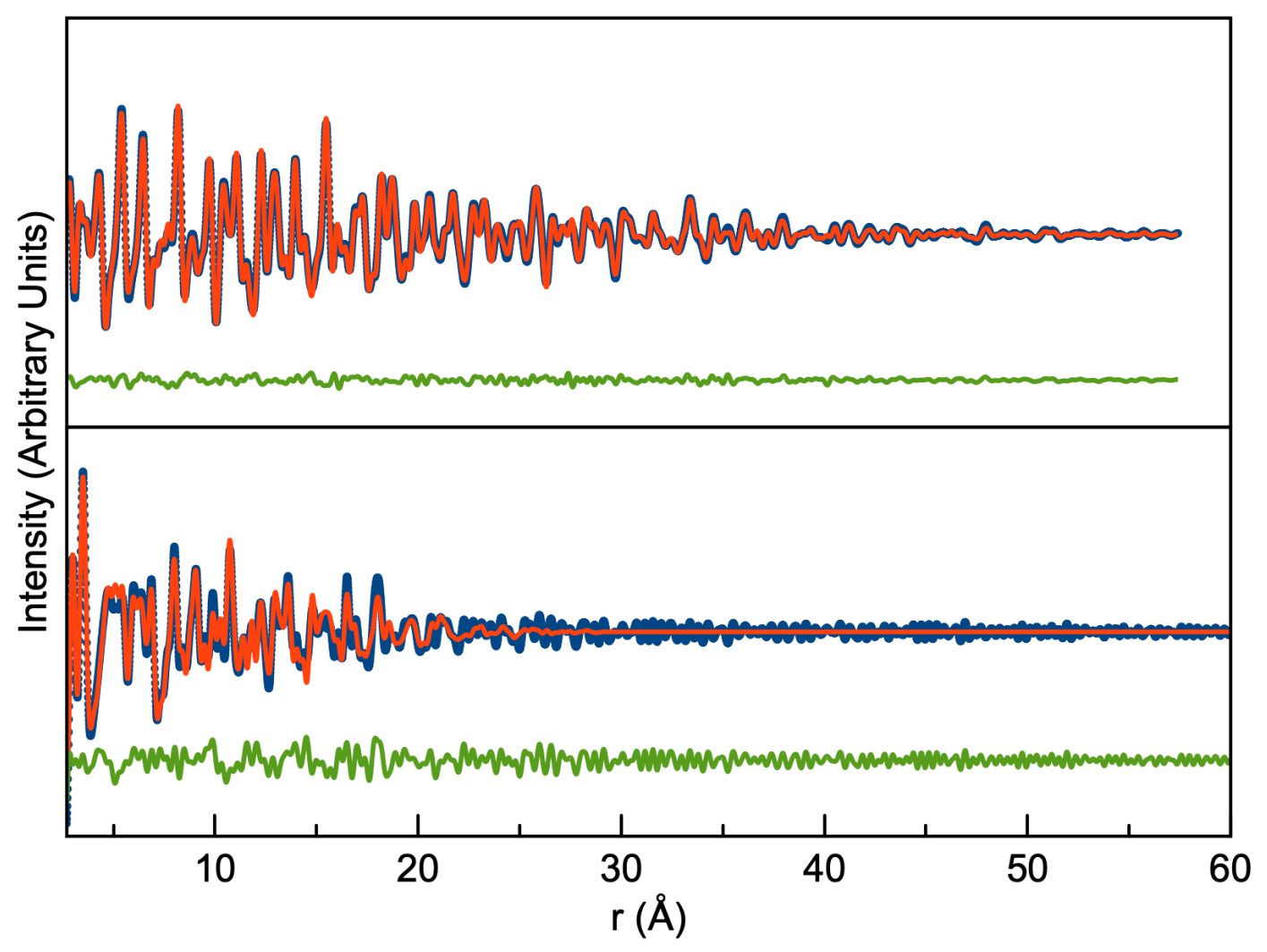

Figure S27. Fits and difference curves for data collected for large and small NCs using the structural model that takes the space group $P 4_{1} 2_{12} 2$. Data for (A) $7.4 \mathrm{~nm} \mathrm{NC}$ and (B) $3.0 \mathrm{~nm} \mathrm{NCs}$ are shown in blue dots. The red line shows the fit to the model and the green line is the difference between the model and the data. 


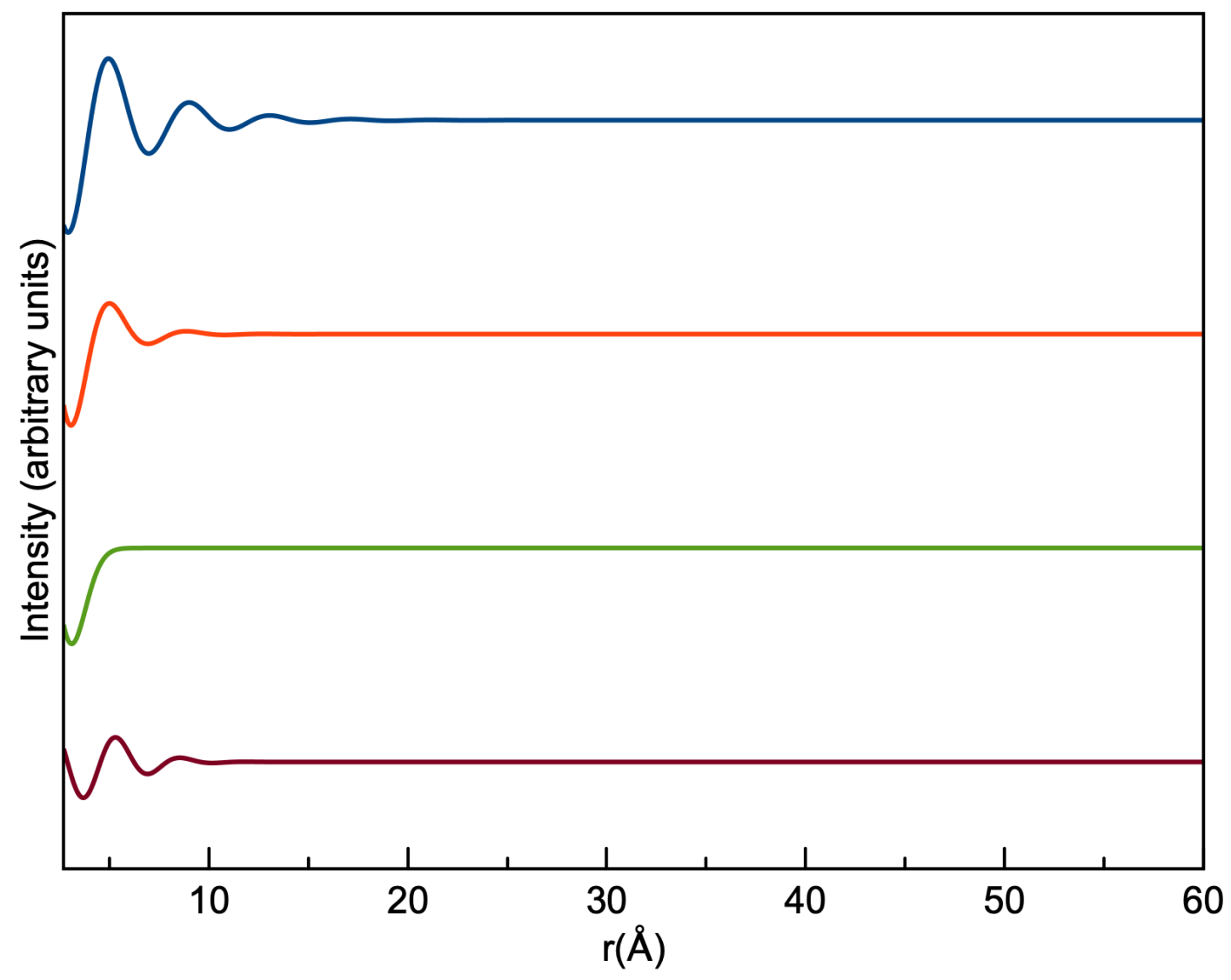

Figure S28. Waves refined using the structural model that takes the space group $P 4_{1} 2_{1} 2$ for four select samples with the smallest $\mathrm{NC}$ at the top and the largest $\mathrm{NC}$ on the bottom of the figure in the same order as Table S1.

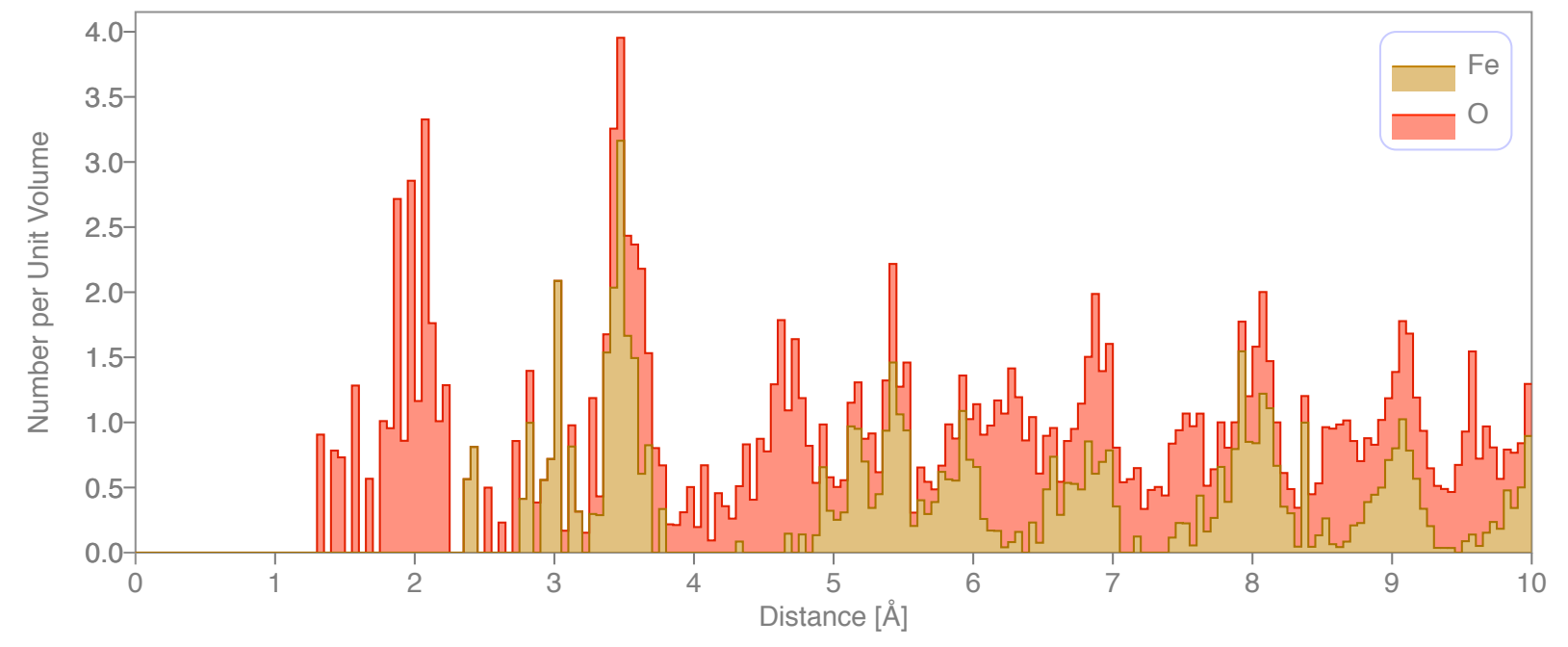

Figure S29. Bond distance histogram for $7.4 \mathrm{~nm}$ NCs (core sizes determined by PDF) using the structural model that takes the space group $P_{1}{ }_{1}{ }_{1} 2$. 


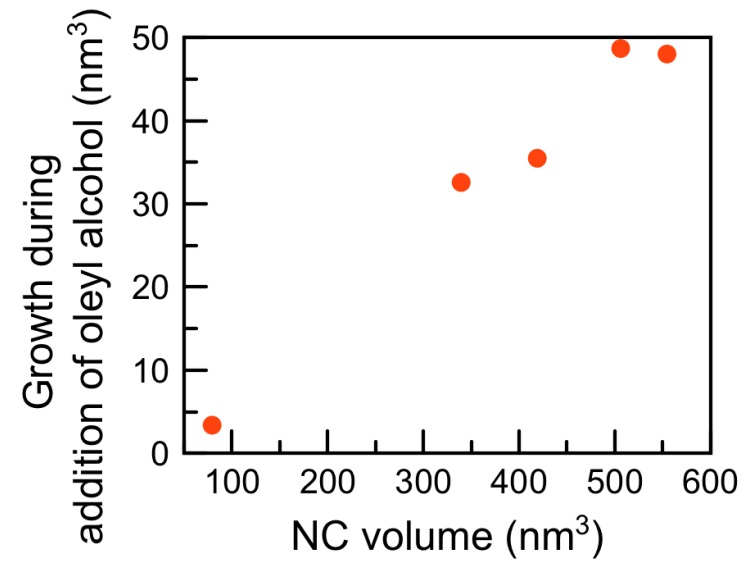

Figure S30. The volume that NCs grow while oleyl alcohol is added to the reaction after $1 \mathrm{mmol}$, $4 \mathrm{mmol}, 5$, mmol, $6 \mathrm{mmol}$ and $7 \mathrm{mmol}$ of precursor has been added (from left to right).

\section{Discussion of Figure 529}

In order to synthesize NCs without experiencing a change in growth rate starting from an $\mathrm{Fe}$ (II) precursor, three $\mathrm{ml}$ of oleyl alcohol is added after every one mmol of iron precursor. ${ }^{8}$ When we stop adding precursor and introduce additional oleyl alcohol to the reaction flask, we are able to determine if any growth happens during periods where there is no precursor being added to the flask. We took samples right after precursor addition stopped and then another aliquot after oleyl alcohol has been added. Growth during this period would indicate that precursor is not reacting as fast as it is being added. After the addition of one mmol of precursor there was very little growth during the addition of oleyl alcohol with only three $\mathrm{nm}^{3}$ volume increase suggesting for these small NCs precursor is reacting as fast as it is being added. After seven mmol of precursor is added however, there is a $50 \mathrm{~nm}^{3}$ volume increase after precursor has stopped being added. This means that unlike in the smaller NCs (after one mmol of precursor had been added) the precursor is no longer reacting as fast as it is being added and excess precursor is remaining in the reaction. 
(1) Schindelin, J.; Arganda-Carreras, I.; Frise, E.; Kaynig, V.; Longair, M.; Pietzsch, T.; Preibisch, S.; Rueden, C.; Saalfeld, S.; Schmid, B.; Tinevez, J.-Y.; White, D. J.; Hartenstein, V.; Eliceiri, K.; Tomancak, P.; Cardona, A. Fiji: An Open-Source Platform for Biological-Image Analysis. Nat. Methods 2012, 9, 676-682.

(2) Fleet, M. E. The Structure of Magnetite. Acta Crystallogr. 1981, 37, 917-920.

(3) Shmakov, A. N.; Krvukova, G. N.; Tsvbulya, S. V; Chuvilin, A. L.; Solovyeva, L. P. Vacancy Ordering in $\gamma-\mathrm{Fe}_{2} \mathrm{O}_{3}$ : Synchrotron X-Ray Powder Diffraction and HighResolution Electron Microscopy Studies. J. Appl. Crystallogr. 1995, 28, 141-145.

(4) Greaves, C. A Powder Neutron Diffraction Investigation of Vacancy Ordering and Covalence in $\gamma-\mathrm{Fe}_{2} \mathrm{O}_{3}$. J. Solid State Chem. 1983, 49, 325-333.

(5) Jørgensen, J.; Mosegaard, L.; Thomsen, L. E.; Jensen, T. R.; Hanson, J. C. Formation of $\gamma-\mathrm{Fe}_{2} \mathrm{O}_{3}$ Nanoparticles and Vacancy Ordering : An In Situ X-Ray Powder Diffraction Study. J. Solid State Chem. 2007, 180, 180-185.

(6) Juhás, P.; Farrow, C. L.; Yang, X.; Knox, K. R.; Billinge, S. J. L. Complex Modeling: A Strategy and Software Program for Combining Multiple Information Sources to Solve Ill Posed Structure and Nanostructure Inverse Problems. Acta Crystallogr., Sect. A: Found. Crystallogr. 2015, A71, 562-568.

(7) Zobel, M.; Neder, R. B.; Kimber, S. A. J. Universal Solvent Restructuring Induced by Colloidal Nanoparticles. Science 2015, 347, 292-294.

(8) Cooper, S. R.; Plummer, L. K.; Cosby, A. G.; Lenox, P.; Jander, A.; Dhagat, P.; Hutchison, J. E. Insights into the Magnetic Properties of Sub-10 nm Iron Oxide Nanocrystals through the Use of a Continuous Growth Synthesis. Chem. Mater. 2018, 30, 6053-6062. 